\title{
Quantifying Activation Rates of Scissile Mechanophores and the Influence of Dispersity
}

\author{
Anna C. Overholts, Molly E. McFadden, and Maxwell J. Robb* \\ Division of Chemistry and Chemical Engineering, California Institute of Technology, Pasadena, \\ California 91125, United States \\ *E-mail: mrobb@caltech.edu
}

\section{Table of Contents}

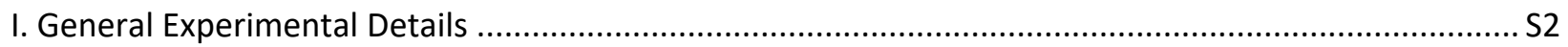

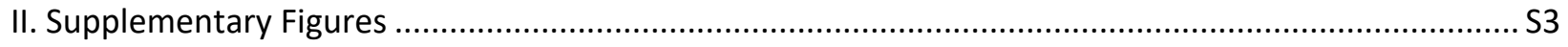

III. Synthesis and Characterization of Initiators and Polymers .............................................................. S8

IV. Description of Sonication Experiments and Fluorescence Spectroscopy.......................................... S11

V. Determination of Total Mechanophore Activation (\%) ..................................................................... S11

VI. Tabulated Data for Determined Rate Constants and $M_{\text {thresh }}$ Values................................................ S13

VII. Tabulated Characterization Data for All Sonication Experiments ................................................. S14

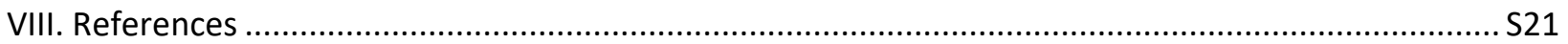

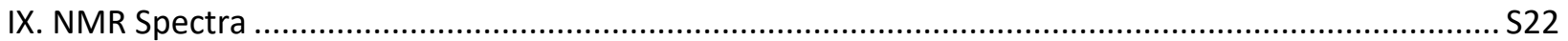




\section{General Experimental Details}

Reagents from commercial sources were used without further purification unless otherwise noted. Methyl acrylate was passed through a short plug of basic alumina to remove inhibitor immediately prior to use. Dry THF and MeCN were obtained from a Pure Process Technology solvent purification system. All reactions were performed under a $\mathrm{N}_{2}$ atmosphere unless specified otherwise.

NMR spectra were recorded using a $400 \mathrm{MHz}$ Bruker Avance III HD with Prodigy Cryoprobe or a $400 \mathrm{MHz}$ Bruker Avance Neo. All ${ }^{1} \mathrm{H}$ NMR spectra are reported in $\delta$ units, parts per million (ppm), and were measured relative to the signals for residual chloroform $(7.26 \mathrm{ppm})$ in deuterated solvent. All ${ }^{13} \mathrm{C} \mathrm{NMR}$ spectra were measured in deuterated solvents and are reported in ppm relative to the signals for chloroform (77.16 ppm). Multiplicity and qualifier abbreviations are as follows: $s=$ singlet, $d=$ doublet, $t$ $\mathrm{q}=$ quartet, $\mathrm{m}=$ multiplet.

High resolution mass spectra (HRMS) were obtained from a JEOL JMS-600H magnetic sector spectrometer equipped with a fast atom bombardment (FAB) ionization source.

Analytical gel permeation chromatography (GPC) was performed using an Agilent 1260 series pump equipped with two Agilent PLgel MIXED-B columns $(7.5 \times 300 \mathrm{~mm})$, an Agilent 1200 series diode array detector, a Wyatt 18-angle DAWN HELEOS light scattering detector, and an Optilab rEX differential refractive index detector. The mobile phase was THF at a flow rate of $1 \mathrm{~mL} / \mathrm{min}$. Molecular weights and molecular weight distributions were calculated by light scattering using a dn/dc value of $0.062 \mathrm{~mL} / \mathrm{g}(25$ ${ }^{\circ} \mathrm{C}$ ) for poly (methyl acrylate) and $0.082 \mathrm{~mL} / \mathrm{g}\left(25^{\circ} \mathrm{C}\right)$ for poly(methyl methacrylate).

Photoluminescence spectra were recorded on a Shimadzu RF-6000 spectrofluorophotometer in a quartz microcuvette (Starna 18F-Q-10-GL14-S).

Photochemical reactions were performed using a 36 W UV100A Honeywell Air Treatment System with a Philips PL-L Hg lamp, or a 4 Watt UVLS-24 EL Series UV Lamp.

Ultrasound experiments were performed inside a sound abating enclosure using a Vibra Cell 505 liquid processor equipped with a 0.5-inch diameter solid probe (part \#630-0217), sonochemical adapter (part \#830-00014), and a Suslick reaction vessel made by the Caltech glass shop (analogous to vessel \#83000014 from Sonics and Materials).

Compounds $\mathbf{S 1},{ }^{1} \mathbf{S 3},{ }^{1} \mathbf{S 4},{ }^{2}$ and $\mathbf{S 6} \mathbf{6}^{3}$ were synthesized following the procedures reported in the literature. Compound $\mathbf{S 2}^{4}$ was synthesized using a modified procedure as described in detail below. 


\section{Supplementary Figures}

Chart S1. Structures of initiators (S1, S2, S3) and small molecule reference compounds (S4 and S5) used in this study.

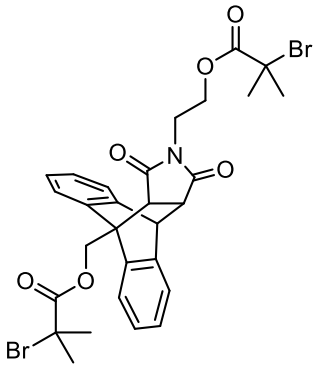

s1

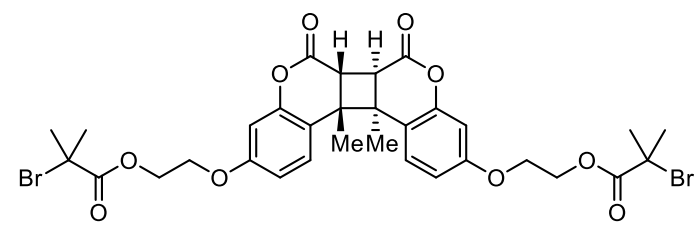

S2

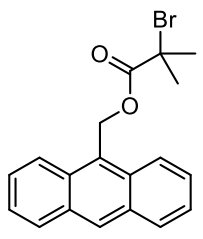

S3

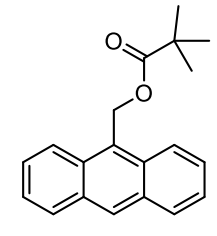

S4<smiles>Cc1cc(=O)oc2cc(OCCOC(=O)C(C)(C)Br)ccc12</smiles>

S5

Chart S2. Structures of polymers PMA-1, PMA-2, PMA-3, and PMMA-1.

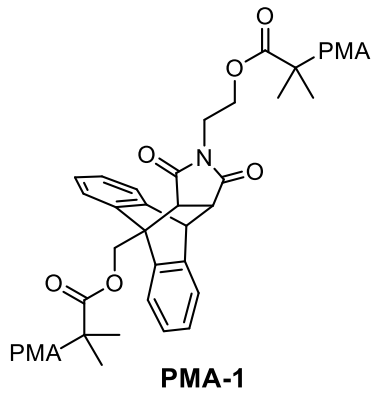<smiles>Cc1cc(=O)oc2cc(OCCOC(=O)C(C)(C)C(=O)O)ccc12</smiles>

PMA-3<smiles>CC(C)(C)C(=O)OCCOc1ccc2c(c1)OC(=O)[C@H]1[C@H]2[C@]2(C)c3ccc(OCCOC(=O)C(C)(C)P)cc3OC(=O)[C@H]12</smiles>

PMA-2<smiles>CCCC(C)(C)C(=O)OCc1c2ccccc2cc2ccccc12</smiles>

PMMA-1 

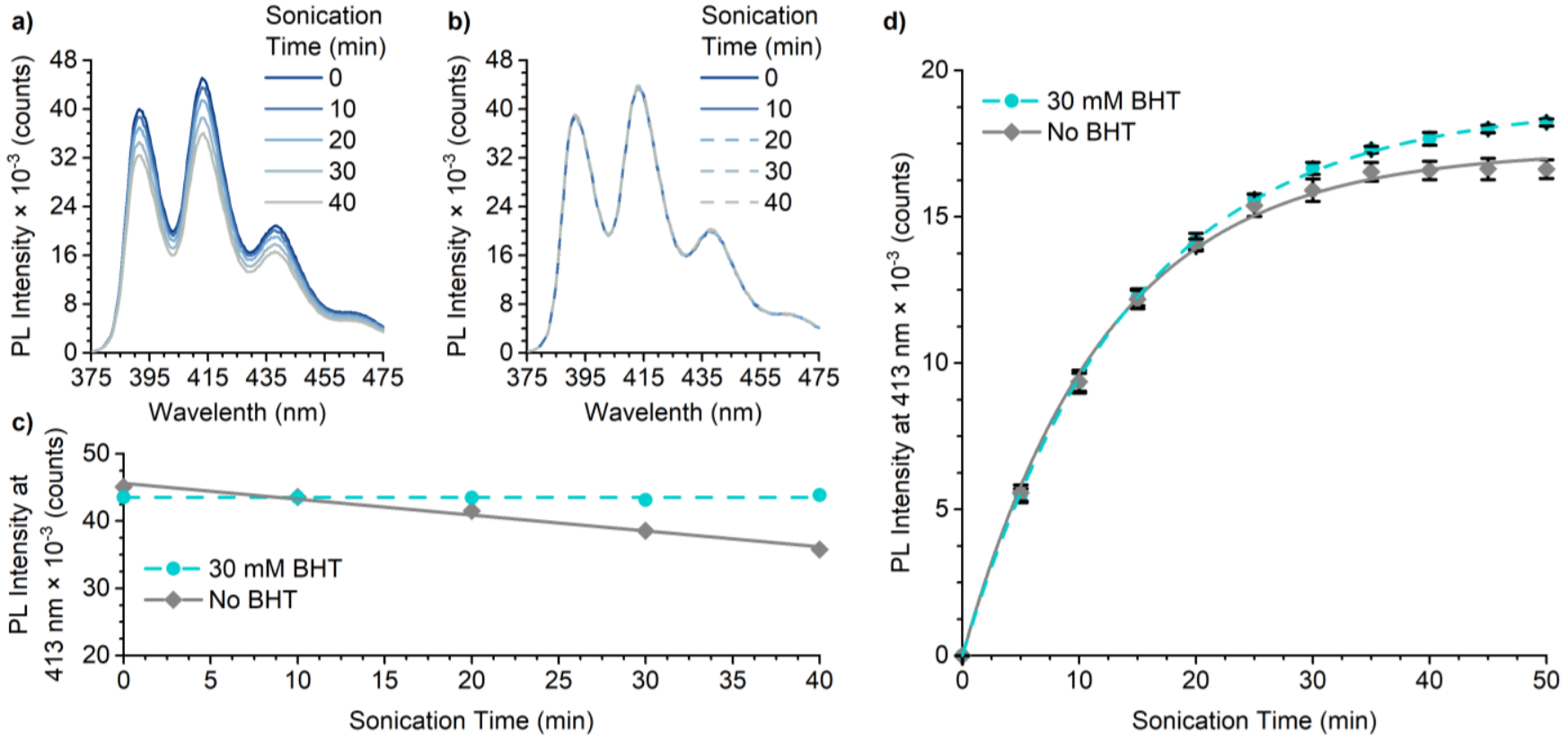

Figure S1. Sonication of anthracene-containing polymers results in anthracene degradation, which can be eliminated by addition of $30 \mathrm{mM}$ BHT stabilizer. (a) Photoluminescence spectra acquired during the sonication of PMMA-1 $\left(2 \mathrm{mg} / \mathrm{mL}\right.$ in pure THF, $\left.\lambda_{\mathrm{ex}}=365 \mathrm{~nm}\right)$ monitoring the attenuation of the anthracene peaks. (b) Photoluminescence spectra acquired during the sonication of PMMA-1 with $30 \mathrm{mM}$ BHT added exhibit no significant change in anthracene fluorescence over time. (c) Time-dependent photoluminescence intensity at 413 $\mathrm{nm}$ for the ultrasonication experiments in panels $a$ and b. (d) Time-dependent photoluminescence intensity at $413 \mathrm{~nm}$ for ultrasonication of 201 kDa PMA-1 in THF illustrating attenuation of the product anthracene signal in the absence of $\mathrm{BHT}$, indicative of degradation. Data are averages of three trials and are fitted to eq 3 .
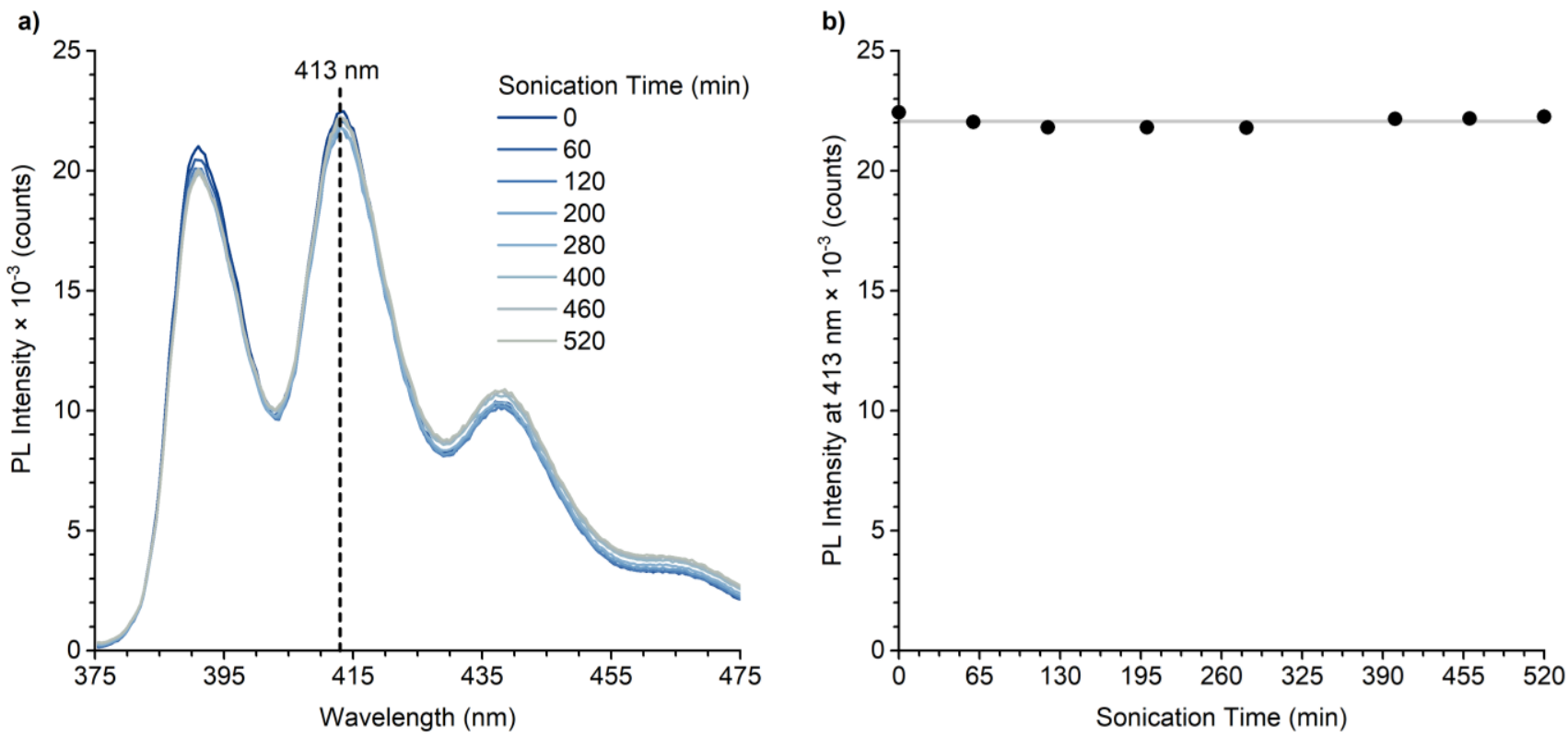

Figure S2. Extended ultrasonication of chain-end functional anthracene polymer PMMA-1 shows negligible evaporation or background fluorescence. (a) Photoluminescence spectra acquired during ultrasonication (2 $\mathrm{mg} / \mathrm{mL}$ THF, $30 \mathrm{mM} \mathrm{BHT}, \lambda_{\mathrm{ex}}=365 \mathrm{~nm}$ ). (b) PL intensity at $413 \mathrm{~nm}$ plotted as a function of sonication time. The grey line is the average intensity value and is included to guide the eye. Experiments were run in duplicate. 

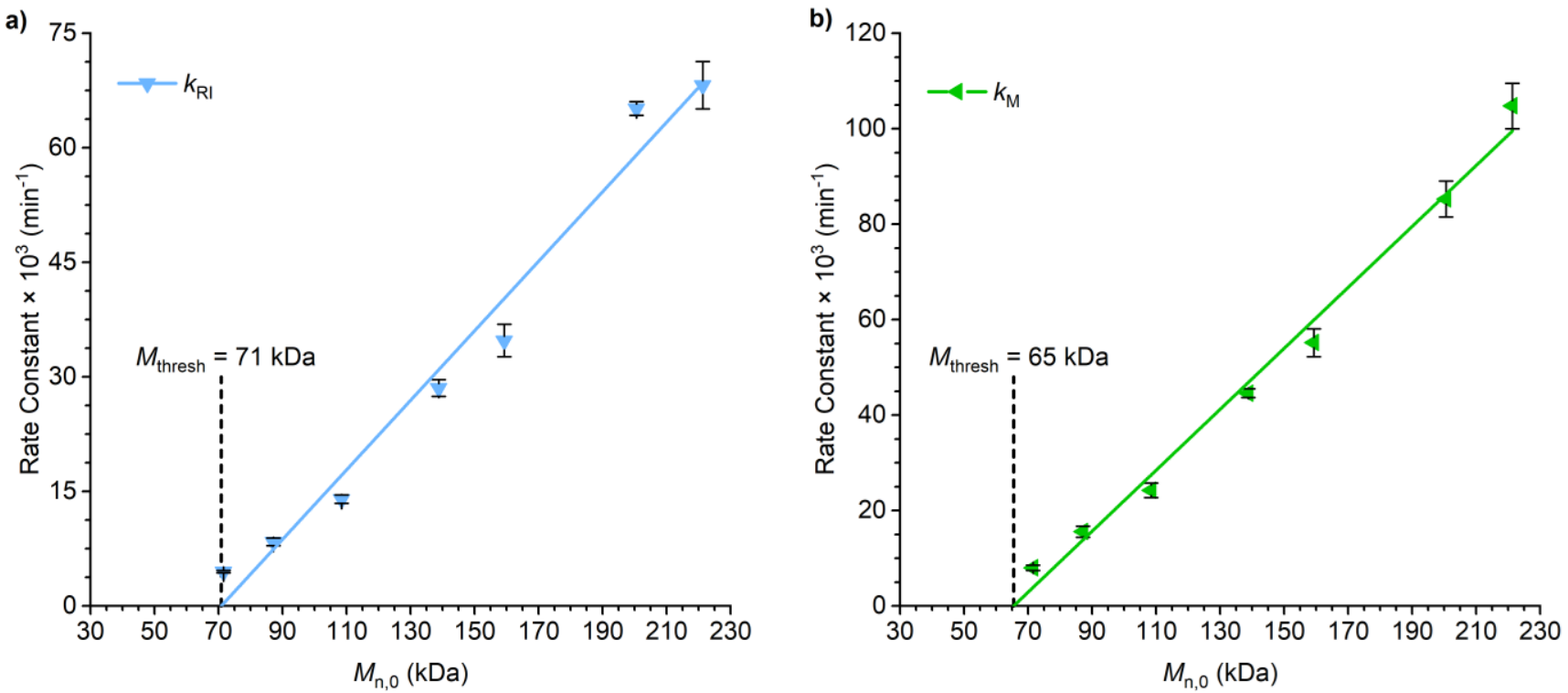

Figure S3. (a) Linear regression of rate constants $\left(k_{\mathrm{RI}}\right)$ determined from GPC-RI measurements for the ultrasoundinduced mechanical activation of PMA-1 with a chain-centered anthracene-maleimide mechanophore in THF provides a $M_{\text {thresh }}$ value of $71 \mathrm{kDa}$. (b) Linear regression of rate constants $\left(k_{\mathrm{M}}\right)$ determined from time-dependent $M_{\mathrm{n}}$ data provides an $M_{\text {thresh }}$ value of $65 \mathrm{kDa}$. Data points and error bars represent average values and standard deviation from three replicate experiments.
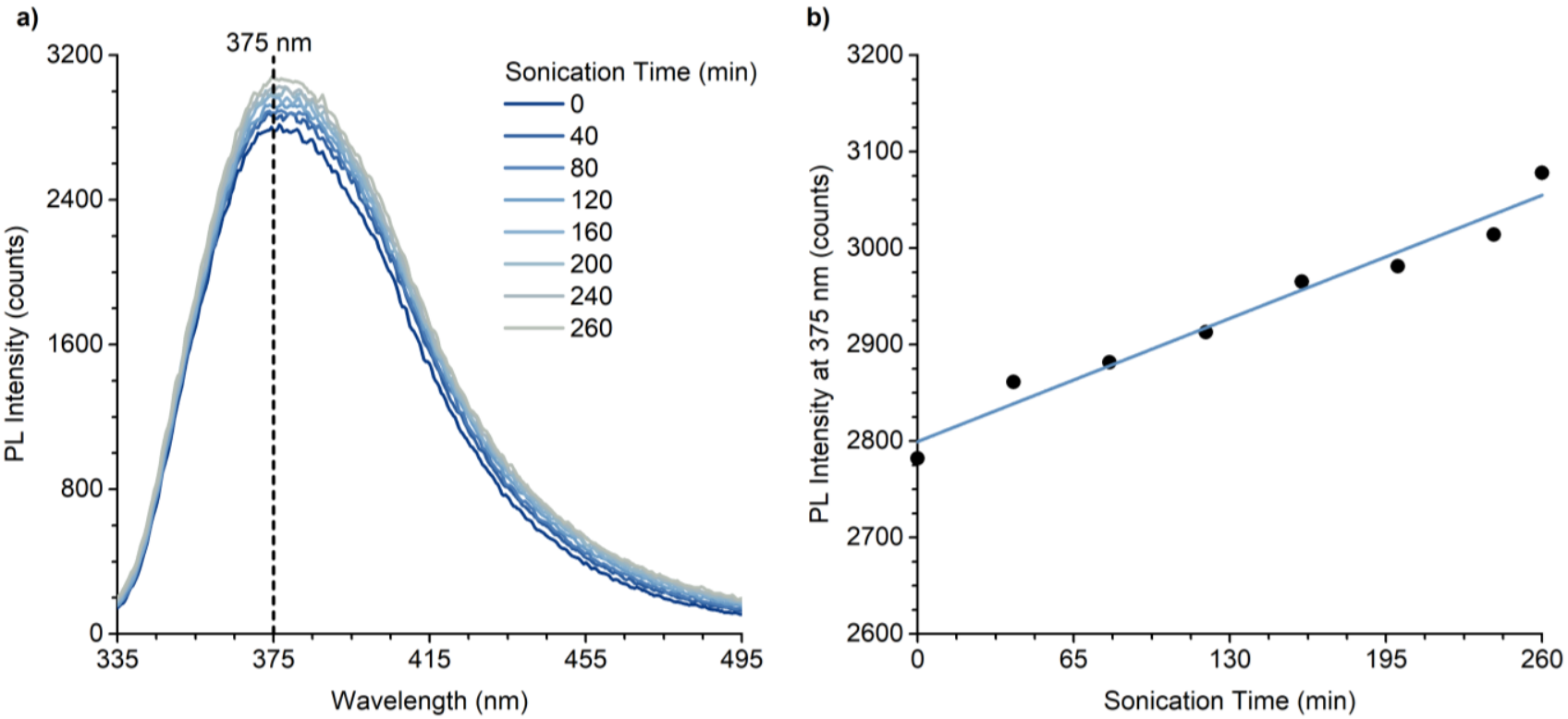

Figure S4. Representative sonication experiment of chain-end functional coumarin polymer PMA-3 for determining a background correction. (a) PL spectra of aliquots removed during sonication, and (b) timedependent PL intensity at $375 \mathrm{~nm}$ fit to a line. Experiments were run in triplicate and the slopes of the linear regressions averaged to obtain a background fluorescence correction factor of $0.796 \mathrm{~min}^{-1}$. 
a)

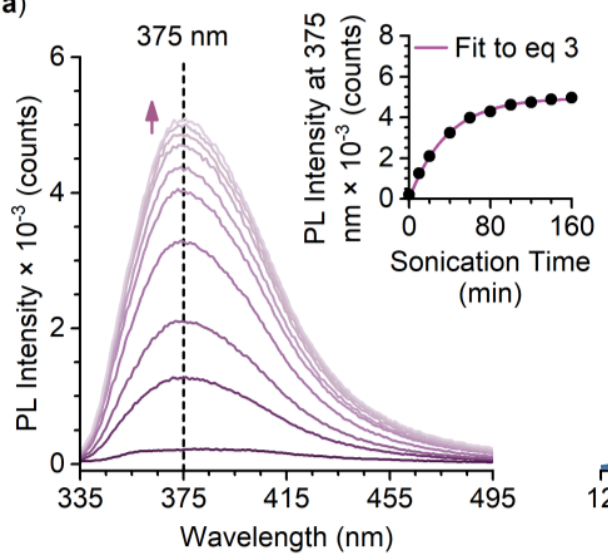

b)

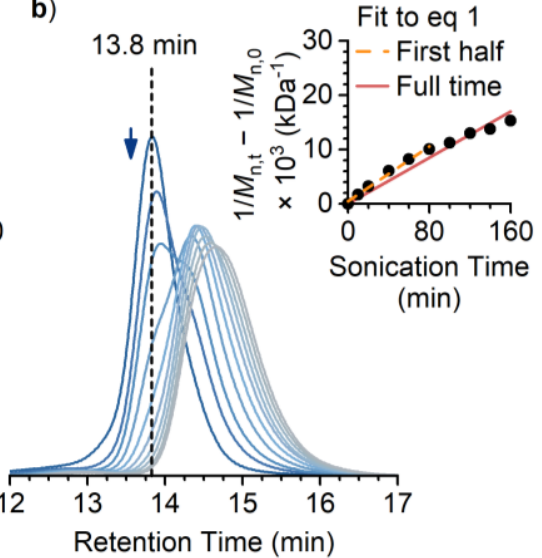

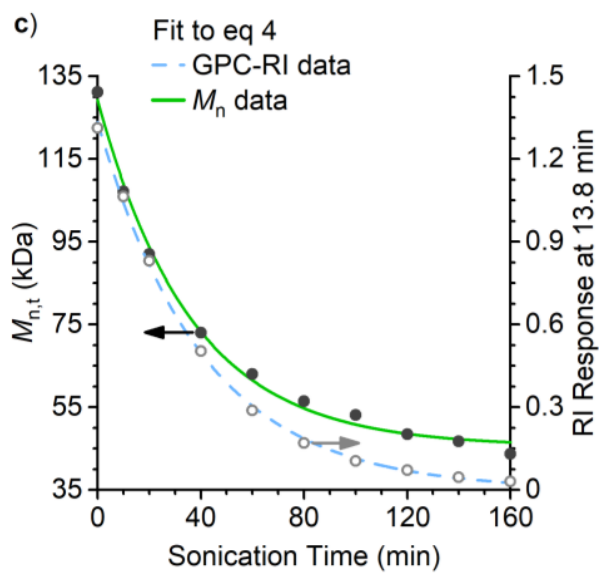

Figure S5. Overview of the different methods for analyzing the rate of ultrasound-induced mechanochemical reaction for a representative PMA-2 containing a chain-centered coumarin dimer mechanophore $\left(M_{\mathrm{n}}=132\right.$ $\mathrm{kg} / \mathrm{mol} ; \quad \Theta=1.06)$. (a) Photoluminescence spectra acquired during ultrasonication $(2 \mathrm{mg} / \mathrm{mL}$ in $3: 1 \mathrm{MeCN} / \mathrm{MeOH}$, $\lambda_{\mathrm{ex}}=320 \mathrm{~nm}$ ), monitoring the generation of coumarin. Inset shows the photoluminescence intensity at $375 \mathrm{~nm}$ as a function of ultrasonication time and fitted to eq 3. (b) Time-dependent GPC traces (RI response) normalized by integrated area exhibiting features characteristic of midchain scission. Inset shows the results of the conventional linearization rate analysis using eq 1 . The fit-determined slope of the linear regression is dependent on the duration of ultrasonication. (c) Alternative analyses performed using the ultrasonication time-dependent GPC data in panel $b$. Values of $M_{\mathrm{n}}$ plotted as a function of ultrasonication time and RI response at $t_{\mathrm{R}}=13.8 \mathrm{~min}$ corresponding to the peak maximum of the unsonicated polymer. Both sets of data are fitted to eq 4.
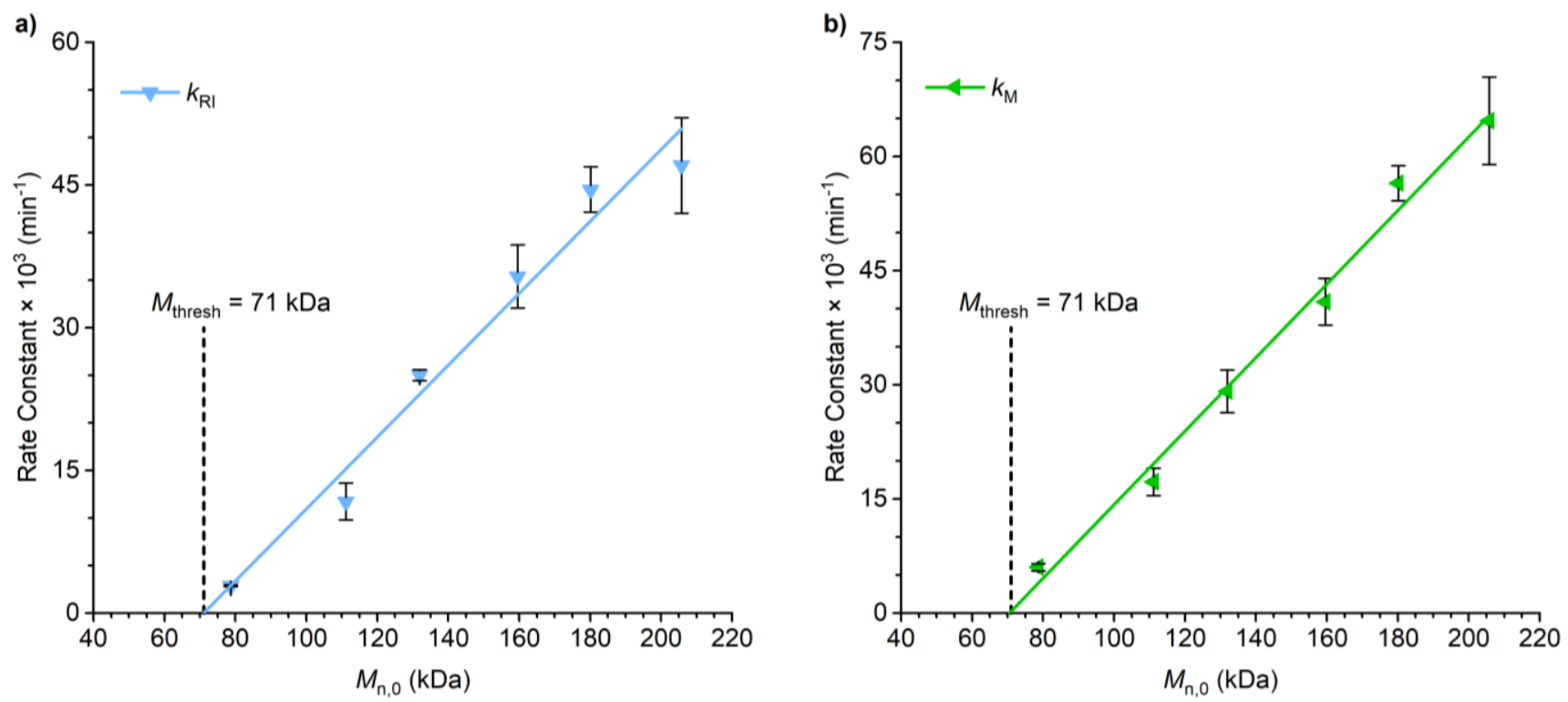

Figure S6. (a) Linear regression of rate constants $\left(k_{\mathrm{RI}}\right)$ determined from GPC-RI measurements for the ultrasoundinduced mechanical activation of PMA-2 with a chain-centered coumarin dimer mechanophore in $\mathrm{MeCN} / \mathrm{MeOH}$ (3:1) provides a $M_{\text {thresh }}$ value of $71 \mathrm{kDa}$. (b) Linear regression of rate constants $\left(k_{\mathrm{M}}\right)$ determined from timedependent $M_{\mathrm{n}}$ data provide an $M_{\text {thresh }}$ value of $71 \mathrm{kDa}$. Data points and error bars represent average values and standard deviation from three replicate experiments. 
a)

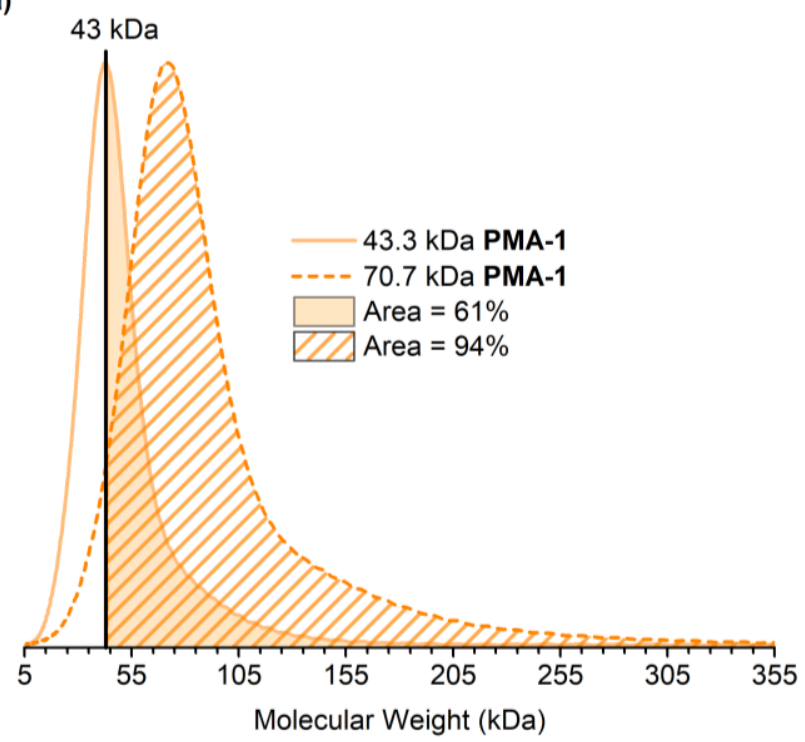

b)

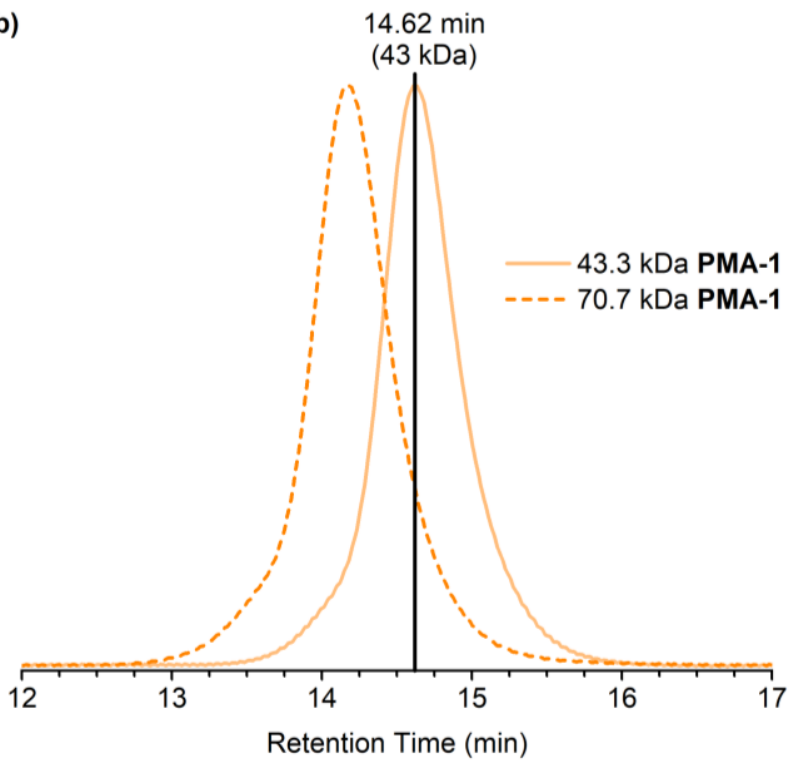

Figure S7. Analysis of the effect of molecular weight distribution on the mechanochemical activation of PMA-1 containing a chain-centered anthracene-maleimide mechanophore with $M_{n}$ below (43.3. kDa) and slightly above (70.7 kDa) the spectroscopically determined value of $M_{\text {thresh }}(65 \mathrm{kDa})$. (a) The area of each GPC chromatogram (RI response) above $43 \mathrm{kDa}$ (denoted by a vertical black line) is $61 \%$ for the $43.3 \mathrm{kDa}$ polymer and $94 \%$ for the 70.7 kDa polymer, consistent with the measured mechanophore activation efficiencies of $64 \pm 4 \%$ and $90 \pm 3 \%$, respectively. These data further support the model describing an explicit chain length below which mechanophore activation does not occur. (b) The same GPC data are plotted in the more conventional format with respect to retention time.

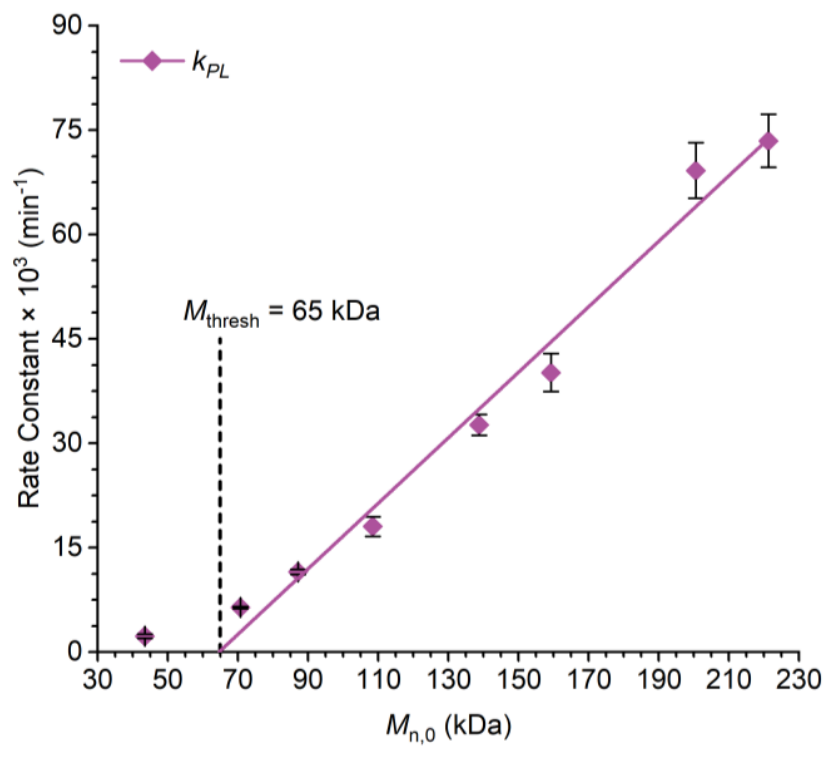

Figure S8. Rate constants determined from PL measurements for the ultrasound-induced mechanical activation of PMA-1 containing a chain-centered anthracene-maleimide mechanophore. The linear regression excludes the data point for the polymer with $M_{n, 0}=43.3 \mathrm{kDa}$, which clearly deviates from the linear trend. Data points and error bars represent average values and standard deviation from three replicate experiments. 


\section{Synthesis and Characterization of Initiators and Polymers}

Scheme S1. Synthesis of Coumarin Dimer Initiator S2

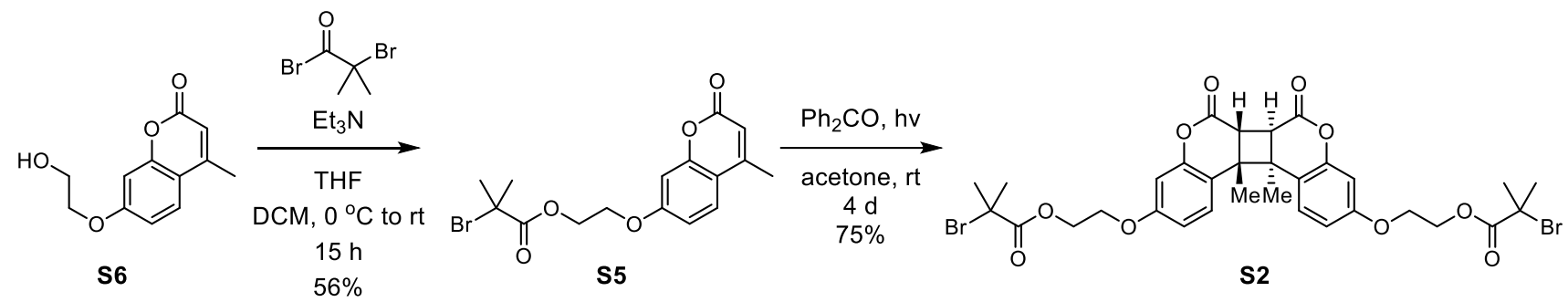

2-((4-methyl-2-oxo-2H-chromen-7-yl)oxy)ethyl 2-bromo-2-methylpropanoate (S5). A flame-dried twoneck flask equipped with a stir bar was charged with $\mathrm{S6}^{3}(1.07 \mathrm{~g}, 4.86 \mathrm{mmol})$, dry THF $(20 \mathrm{~mL})$, and dry DCM (45 mL). The mixture was stirred until all solids dissolved followed by the addition of triethylamine $(1 \mathrm{~mL}, 7.18 \mathrm{mmol})$. The reaction was cooled to $0{ }^{\circ} \mathrm{C}$, after which $\alpha$-bromoisobutyryl bromide $(0.9 \mathrm{~mL}, 7.28$ $\mathrm{mmol}$ ) was added slowly. After addition was complete, the reaction was removed from the ice bath and warmed to room temperature. After stirring for $15 \mathrm{~h}$, an aqueous solution of saturated $\mathrm{NH}_{4} \mathrm{Cl}(50 \mathrm{~mL})$ was added and the organic layer was separated. The aqueous layer was extracted with DCM ( $3 \times 50 \mathrm{~mL})$ and the combined organic layers were washed with brine $(50 \mathrm{~mL})$. The organic phase was dried over $\mathrm{MgSO}_{4}$, filtered, and concentrated under reduced pressure. The crude mixture was redissolved in EtOAc $(50 \mathrm{~mL})$ and washed with $1 \mathrm{M} \mathrm{NaOH}(3 \times 15 \mathrm{~mL})$ and then brine $(15 \mathrm{~mL})$. The organic phase was dried over $\mathrm{MgSO}_{4}$, filtered, and concentrated under reduced pressure. The crude material was recrystallized from DCM/hexanes to yield the title compound as a white crystalline solid (1.00 g, 56\%).

$\underline{\operatorname{TLC}(20 \% \text { EtOAC/hexanes): }} \mathrm{R}_{f}=0.24$

${ }^{1} \mathrm{H} \mathrm{NMR}(400 \mathrm{MHz}, \mathrm{CDCl} 3) \delta: 7.51(\mathrm{~d}, J=8.8 \mathrm{~Hz}, 1 \mathrm{H}), 6.88(\mathrm{dd}, J=8.8,2.5 \mathrm{~Hz}, 1 \mathrm{H}), 6.83(\mathrm{~d}, J=2.5 \mathrm{~Hz}, 1 \mathrm{H})$, 6.15 (broad q, $J=1.3 \mathrm{~Hz}, 1 \mathrm{H}), 4.61-4.50(\mathrm{~m}, 2 \mathrm{H}), 4.34-4.23(\mathrm{~m}, 2 \mathrm{H}), 2.40(\mathrm{~d}, J=1.2 \mathrm{~Hz}, 3 \mathrm{H}), 1.94(\mathrm{~s}, 6 \mathrm{H})$.

${ }^{13} \mathrm{C}\left\{{ }^{1} \mathrm{H}\right\}$ NMR $(101 \mathrm{MHz}, \mathrm{CDCl} 3) \delta: 171.7,161.5,161.3,155.3,152.6,125.8,114.2,112.7,112.4,101.9$, $66.2,63.8,55.46,30.8,18.8$.

HRMS (ESI, $m / z):$ calcd for $\left[\mathrm{C}_{16} \mathrm{H}_{18} \mathrm{BrO}_{5}\right]^{+}(\mathrm{M}+\mathrm{H})^{+} 369.0338$, found 369.0358 .

(((6aR,6bR,12bR,12cR)-12b,12c-dimethyl-6,7-dioxo-6,6a,6b,7,12b,12c-hexahydrocyclobuta[1,2-c:4,3c']dichromene-3,10-diyl)bis(oxy))bis(ethane-2,1-diyl) bis(2-bromo-2-methylpropanoate) (S2). Compound S5 $(1.00 \mathrm{~g}, 2.71 \mathrm{mmol})$ and benzophenone $(244 \mathrm{mg}, 1.34 \mathrm{mmol})$ were added to a $20 \mathrm{~mL}$ scintillation vial equipped with a stir bar and a septum cap. Acetone $(8 \mathrm{~mL})$ was added and the solution was sparged with $\mathrm{N}_{2}$ for 30 min. The vial was partially submerged in a water bath and irradiated with a high pressure mercury lamp ( $36 \mathrm{~W}$ ) while stirring for 4 days. The solution was then concentrated under reduced pressure and the crude material eluted through a plug of silica gel, first with $20 \% \mathrm{EtOAC} / \mathrm{hexanes}$ then with EtOAc. The former eluent was discarded and the latter portion was collected and concentrated under reduced pressure. The crude material was recrystallized from EtOAc/hexanes to yield the title compound as a white crystalline solid (749 mg, 75\%). ${ }^{1} \mathrm{H}$ and ${ }^{13} \mathrm{C}$ NMR spectra match the characterization data reported previously. ${ }^{4}$ 
ILC (20\% EtOAc/hexanes): $\mathrm{R}_{f}=0.15$

${ }^{1} \mathrm{H} \mathrm{NMR}(400 \mathrm{MHz}, \mathrm{CDCl} 3) \delta: 7.05(\mathrm{~d}, J=8.6 \mathrm{~Hz}, 2 \mathrm{H}), 6.80$ (dd, $\left.J=8.6,2.6 \mathrm{~Hz}, 2 \mathrm{H}\right), 6.65(\mathrm{~d}, J=2.6 \mathrm{~Hz}, 2 \mathrm{H})$, $4.58-4.51(\mathrm{~m}, 4 \mathrm{H}), 4.28-4.20(\mathrm{~m}, 4 \mathrm{H}), 3.38(\mathrm{~s}, 2 \mathrm{H}), 1.95(\mathrm{~s}, 12 \mathrm{H}), 1.24(\mathrm{~s}, 6 \mathrm{H})$.

${ }^{13} \mathrm{C}\left\{{ }^{1} \mathrm{H}\right\}$ NMR $\left(101 \mathrm{MHz}^{\mathrm{CDCl}}{ }_{3}\right) \delta: 171.8,166.0,159.3,151.8,128.3,115.8,112.6,103.5,66.1,64.0,55.5$, $46.8,45.1,30.9,26.5$.

Representative Procedure for the Synthesis of Poly(Methyl Acrylate) (PMA) Polymer Containing a ChainCentered Mechanophore. PMA polymers were synthesized by controlled radical polymerization following the procedure by Nguyen et al. ${ }^{5}$ A $25 \mathrm{~mL}$ Schlenk flask equipped with a stir bar was charged with initiator S2 (16.7 mg, $0.226 \mathrm{mmol})$, DMSO $(2 \mathrm{~mL})$, methyl acrylate $(2 \mathrm{~mL})$, and freshly cut copper wire $(2.0 \mathrm{~cm}$ length, 20 gauge). The flask was sealed, the solution was deoxygenated with three freeze-pump-thaw cycles, and then allowed to warm to $\mathrm{rt}$ and backfilled with nitrogen. Me ${ }_{6} \operatorname{TREN}(17 \mu \mathrm{L}, 0.0636 \mathrm{mmol})$ was added via microsyringe. After stirring at $\mathrm{rt}$ for $2 \mathrm{~h}$, the flask was opened to air and the solution was diluted with DCM. The polymer solution was precipitated into cold methanol ( $3 \mathrm{x})$ and the isolated material was dried under vacuum to yield $1.46 \mathrm{~g}$ of PMA-2 (70\%). $M_{\mathrm{n}}=78.7 \mathrm{kDa}, \Theta=1.05$.

Synthesis of Chain-End Functional Control Polymer PMMA-1 Containing an Anthracene End Group. A 25 $\mathrm{mL}$ Schlenk flask equipped with a stir bar was charged with initiator 3 (7.7 mg, $0.0216 \mathrm{mmol}$ ), DMSO (5 $\mathrm{mL})$, methyl methacrylate $(5 \mathrm{~mL})$, and freshly cut copper wire $(2.0 \mathrm{~cm}$ length, 20 gauge). The flask was sealed, the solution was deoxygenated with three freeze-pump-thaw cycles, and then allowed to warm to $\mathrm{rt}$ and backfilled with nitrogen. PMDETA (11 $\mu \mathrm{L}, 0.0527 \mathrm{mmol})$ was added via microsyringe. After stirring at $\mathrm{rt}$ for $47 \mathrm{~h}$, the flask was opened to air and the solution was diluted with DCM. The polymer solution was precipitated into cold methanol $(3 \mathrm{x})$ and the isolated material was dried under vacuum to yield 1.49 $\mathrm{g}$ of PMMA-1 (28\%). $M_{\mathrm{n}}=140 \mathrm{kDa}, \emptyset=1.89$.

Synthesis of Chain-End Functional Polymer PMA-3 Containing a Coumarin End Group. PMA-2 (20.0 mg, $160 \mathrm{kDa}, \emptyset=1.05)$ was dissolved in a 3:1 mixture of $\mathrm{MeCN} / \mathrm{MeOH}(50 \mathrm{~mL})$ in a quartz tube equipped with a stir bar and sealed with a rubber septum. The solution was irradiated with UV light $(254 \mathrm{~nm})$ for $60 \mathrm{~min}$, then stored in the dark. Analysis by GPC provided a measured $M_{\mathrm{n}}$ of $78.7 \mathrm{kDa}(\Theta=1.07)$, approximately one-half the initial $M_{\mathrm{n}}$ (see Table S1). Analysis by ${ }^{1} \mathrm{H}$ NMR spectroscopy confirmed complete conversion of PMA-2 to PMA-3 (Figure S9).

Table S1. Summary of $M_{\mathrm{n}}$ and $\oslash$ data for PMA-1, PMA-2, PMA-3, and PMMA-1.

\begin{tabular}{|c|c|c|c|c|c|}
\hline & $M_{\mathrm{n}}(\mathrm{kDa})$ & $\boldsymbol{\theta}$ & & $M_{\mathrm{n}}(\mathrm{kDa})$ & $\boldsymbol{\theta}$ \\
\hline \multirow{8}{*}{ PMA-1 } & 43.3 & 1.05 & \multirow{6}{*}{ PMA-2 } & 78.7 & 1.05 \\
\hline & 70.7 & 1.07 & & 111 & 1.07 \\
\hline & 87.1 & 1.05 & & 132 & 1.06 \\
\hline & 108 & 1.06 & & 160 & 1.05 \\
\hline & 139 & 1.05 & & 180 & 1.05 \\
\hline & 159 & 1.06 & & 206 & 1.09 \\
\hline & 201 & 1.07 & PMA-3 & 78.7 & 1.07 \\
\hline & 221 & 1.10 & PMMA-1 & 140 & 1.89 \\
\hline
\end{tabular}



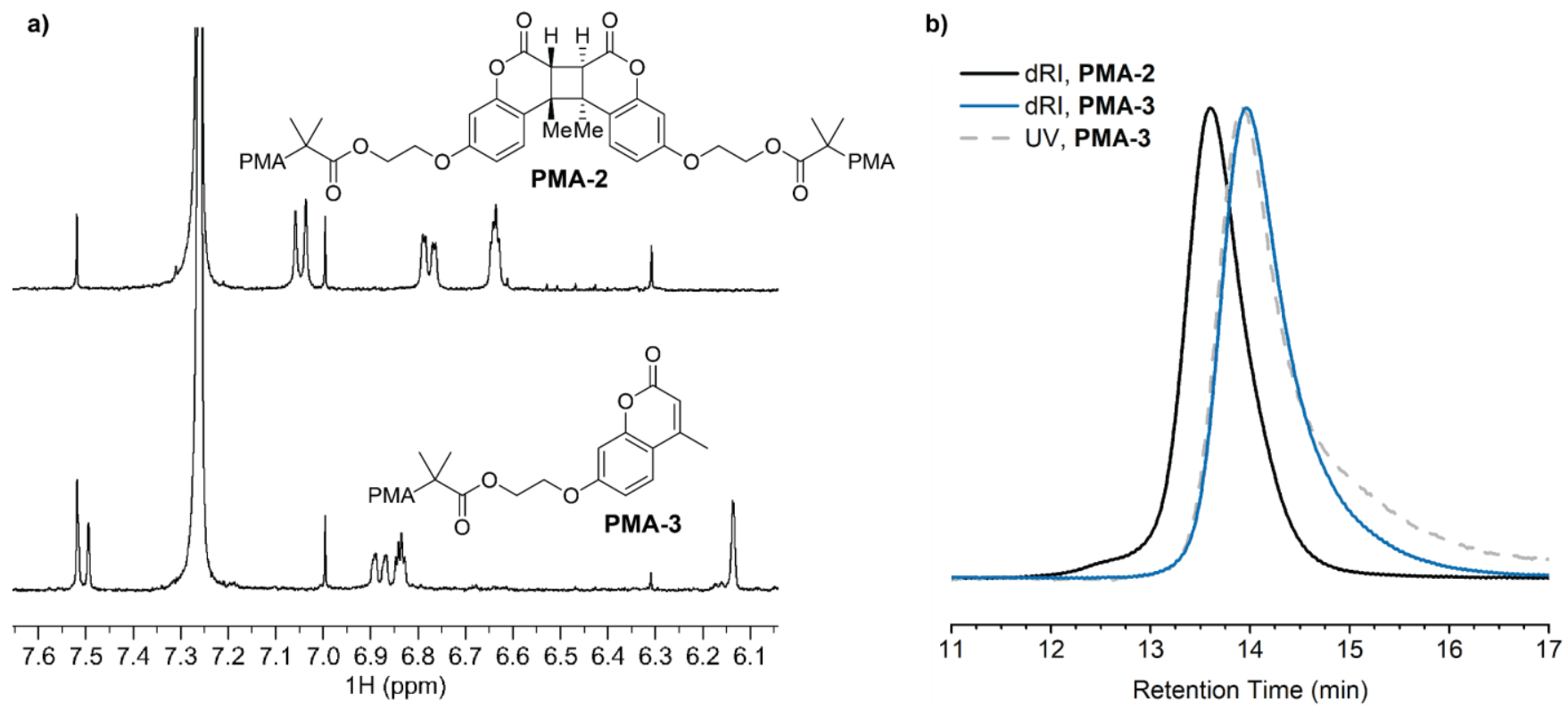

Figure S9. Characterization of the photochemical cleavage of PMA-2 to produce coumarin chain-end functional polymer PMA-3. (a) Partial ${ }^{1} \mathrm{H}$ NMR spectra demonstrating complete conversion of the coumarin dimer after irradiation with $254 \mathrm{~nm}$ UV light. (b) GPC traces (RI response) demonstrating a clean shift in retention time from starting material PMA-2 (black line) to cleaved product PMA-3 after photoirradiation (blue line). Monitoring the GPC elution with a UV detector at $320 \mathrm{~nm}$ (dashed gray line) corresponding to the absorption of coumarin confirms chain-end functionality.
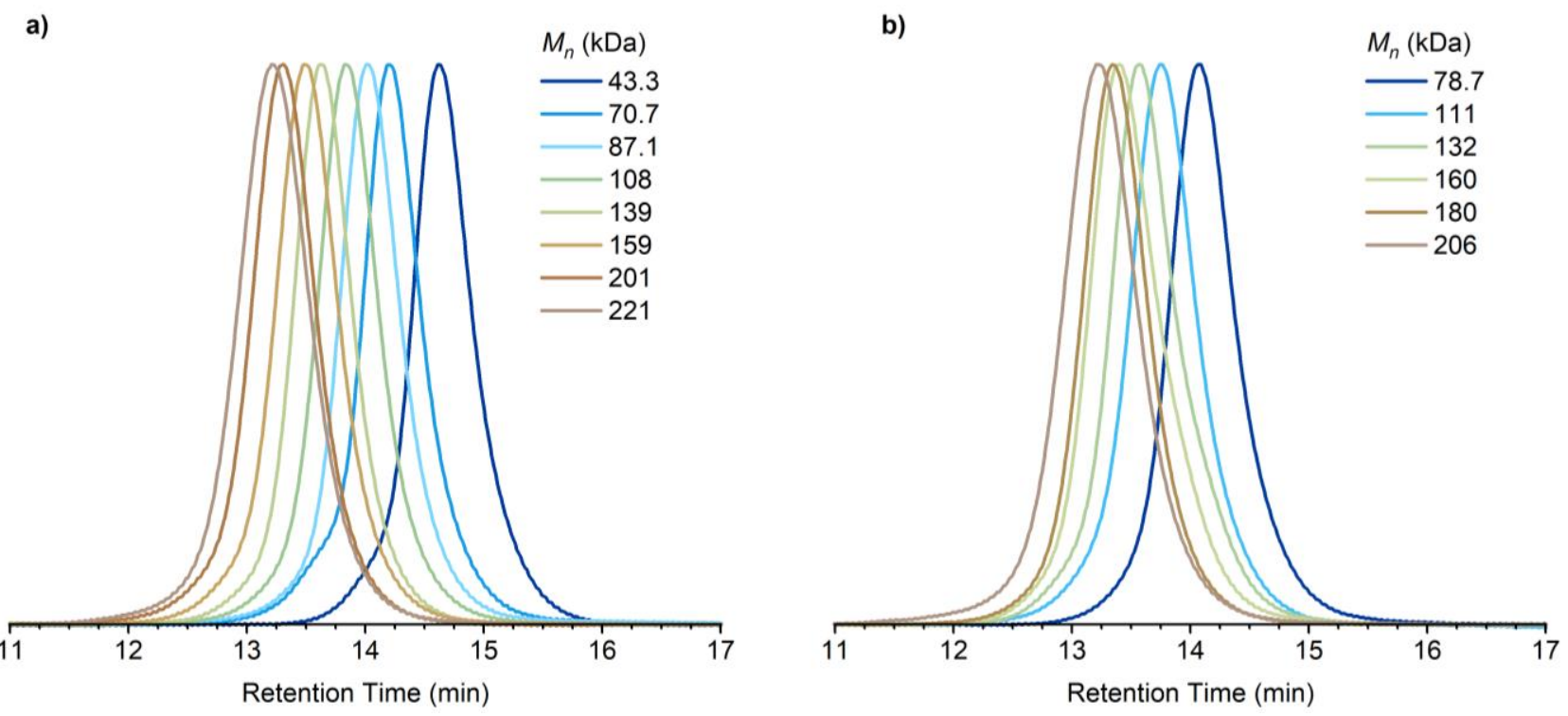

Figure S10. GPC traces (RI response) of polymers used in this study containing a chain-centered mechanophore. (a) PMA-1 series (anthracene-maleimide), and (b) PMA-2 series (coumarin dimer). 


\section{Description of Sonication Experiments and Fluorescence Spectroscopy}

General Procedure for Ultrasonication Experiments. An oven-dried sonication vessel was fitted with rubber septa, placed onto the sonication probe, and allowed to cool under a stream of dry argon. The vessel was charged with a solution of the polymer in anhydrous solvent (THF or 3:1 MeCN/MeOH, 2.0 $\mathrm{mg} / \mathrm{mL}, 20 \mathrm{~mL}$ ) and submerged in an ice bath. The solution was sparged continuously with argon beginning $10 \mathrm{~min}$ prior to sonication and for the duration of the sonication experiment. Pulsed ultrasound $(1 \mathrm{~s}$ on $/ 2$ s off, $30 \%$ amplitude, $\left.20 \mathrm{kHz}, 13.6 \mathrm{~W} / \mathrm{cm}^{2}\right)$ was then applied to the system. Aliquots $(1.0 \mathrm{~mL})$ were removed at specified time points (sonication "on" time) and filtered through a $0.45 \mu \mathrm{m}$ PTFE syringe filter prior to analysis by GPC and fluorescence spectroscopy. Ultrasonic intensity was calibrated using the method described by Berkowski et al. ${ }^{6}$

Analysis of Sonicated Polymer Samples by Fluorescence Spectroscopy. Aliquots from the sonication experiment were added to a microcuvette. Emission spectra for PMA-1 and PMMA-1 were recorded at 375-480 nm using an excitation wavelength of $\lambda_{\mathrm{ex}}=365 \mathrm{~nm}$. Emission spectra for polymers PMA-2 and PMA-3 were recorded at 330-500 nm using an excitation wavelength of $\lambda_{\mathrm{ex}}=320 \mathrm{~nm}$.

\section{Determination of Total Mechanophore Activation (\%)}

Characterization of Activation Efficiency for the Anthracene-Maleimide Mechanophore. Samples of S4 in THF at various concentrations were prepared and PL spectra were acquired to construct the calibration curve shown in Figure S11. The theoretical PL intensity for each sonication experiment based on the concentration of mechanophore was determined from this calibration curve and used as the value for $100 \%$ activation.

Calculation of Percent Activation for the Anthracene-Maleimide Mechanophore. Time-dependent PL values at the relevant emission wavelength (413 nm for PMA-1) were fit to eq 3 . The fit-determined plateau value $(A)$ was used as the maximum activation for that sonication experiment (see Figures S12 and S13 for representative examples). The predicted plateau value $(A)$ determined from each experiment was then divided by the PL value calculated for full conversion (i.e., 100\% mechanophore activation) as described above. 

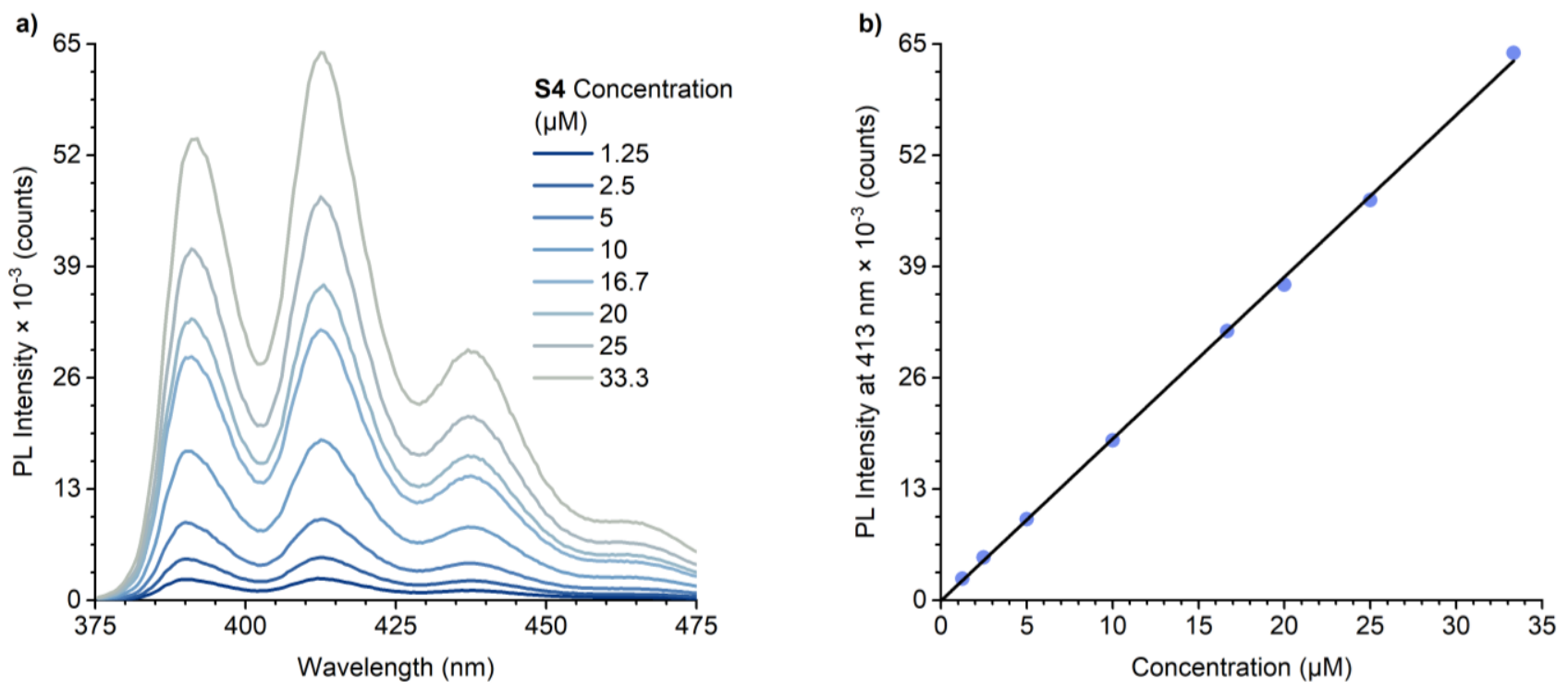

Figure S11. Construction of a calibration curve for experimental determination of the concentration of anthracene-containing polymer. (a) Photoluminescence emission spectra ( $\lambda_{\mathrm{ex}}=365 \mathrm{~nm}$ ), and (b) PL intensity at $413 \mathrm{~nm}$ for solutions of compound S4 in THF as a function of concentration. A linear regression of the data in (b) gives the calibration function $y=1893^{*} x$.
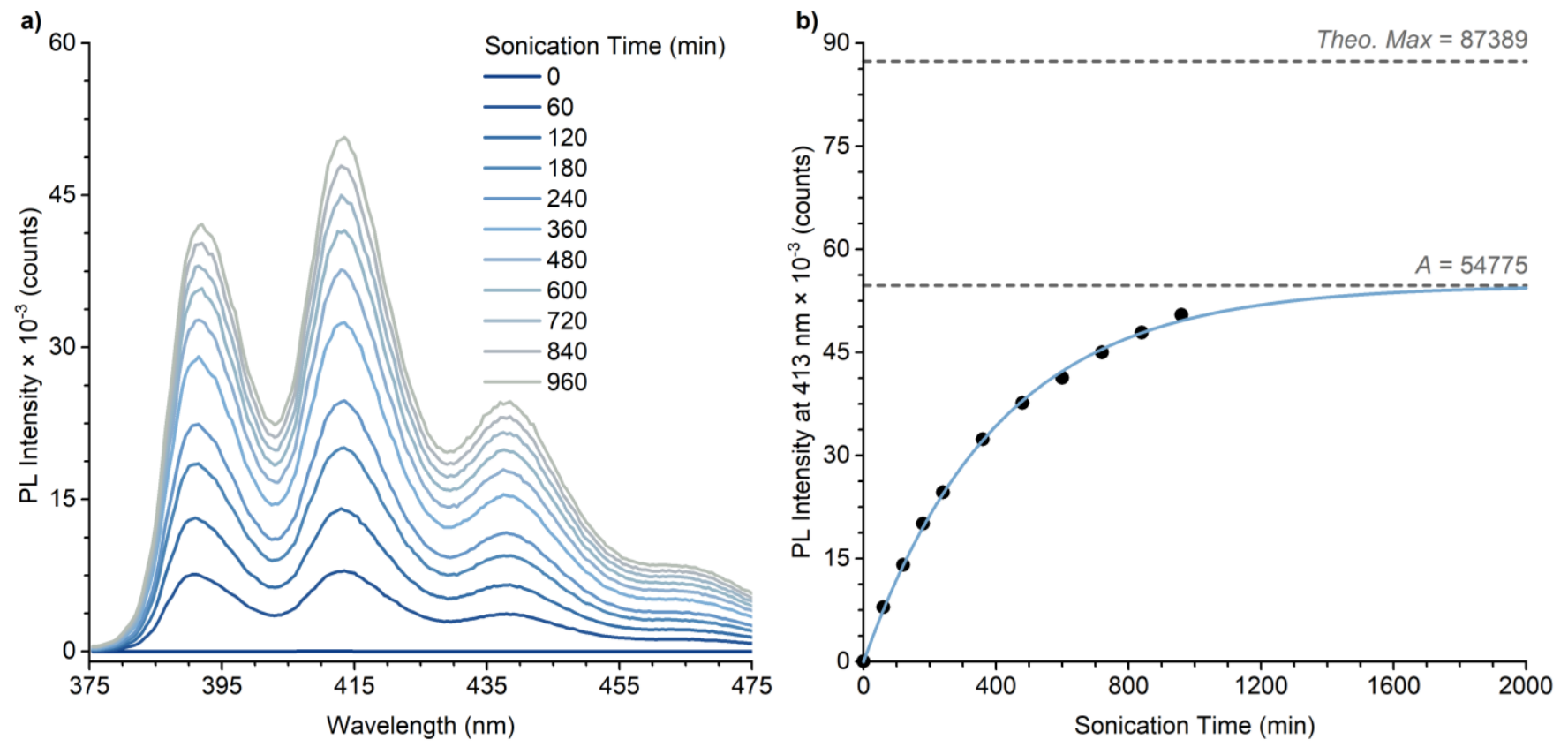

Figure S12. (a) Representative PL measurements for polymer PMA-1 $\left(M_{\mathrm{n}}=43.3 \mathrm{~kg} / \mathrm{mol} ; \emptyset=1.05\right)$ containing a chain-centered anthracene-maleimide mechanophore. (b) Photoluminescence intensity at $413 \mathrm{~nm}$ as a function of ultrasonication time, which is fitted to eq 3 to determine the plateau PL intensity, $A$. The predicted plateau value $A$ is compared to the maximum theoretical PL intensity determined from the calibration curve and based on the concentration of mechanophore in order to derive percent activation. 

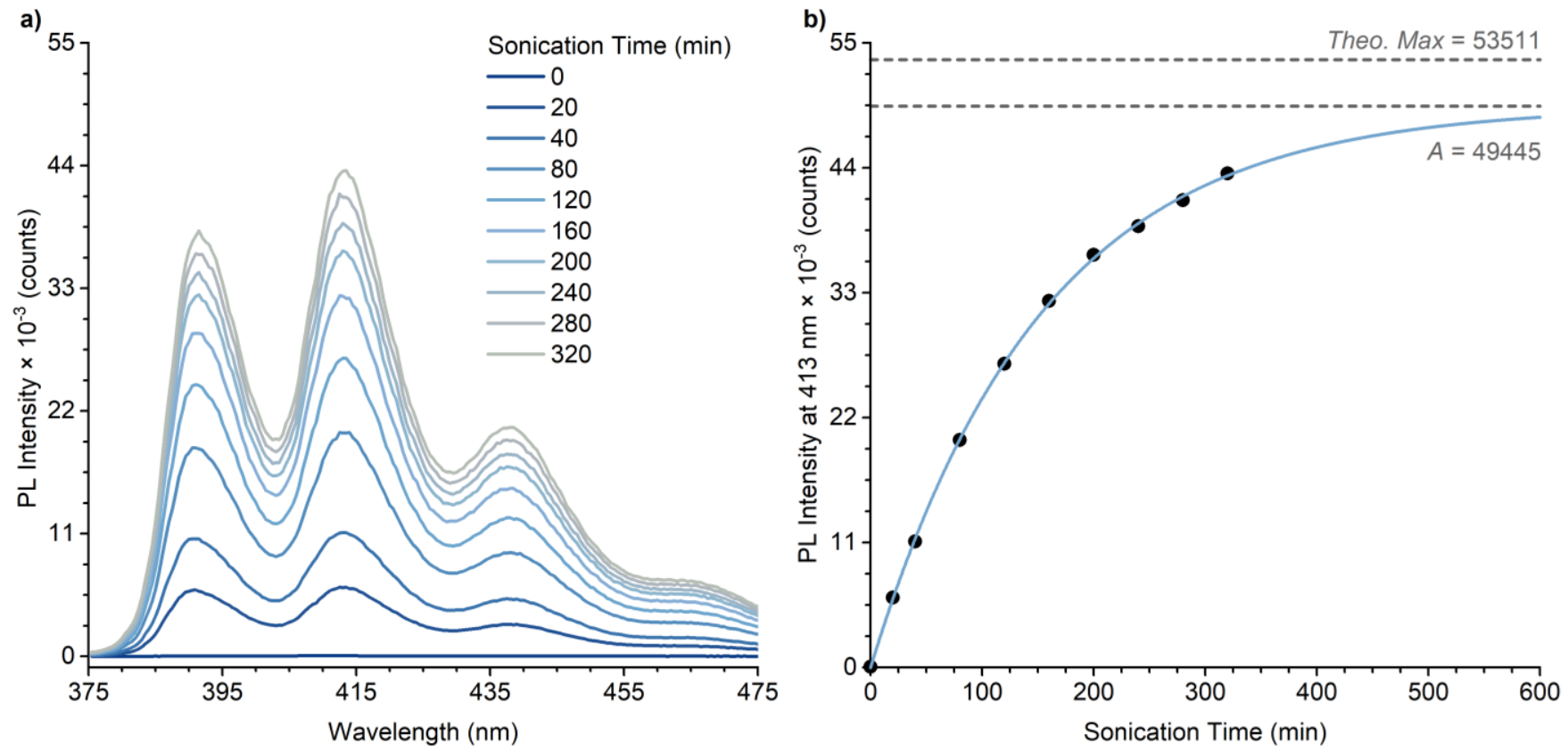

Figure S13. (a) Representative PL measurements for polymer PMA-1 $\left(M_{\mathrm{n}}=70.7 \mathrm{~kg} / \mathrm{mol} ; \quad \theta=1.07\right)$ containing a chain-centered anthracene-maleimide mechanophore. (b) Photoluminescence intensity at $413 \mathrm{~nm}$ as a function of ultrasonication time, which is fitted to eq 3 to determine the plateau PL intensity, $A$. The predicted plateau value $A$ is compared to the maximum theoretical PL intensity determined from the calibration curve and based on the concentration of mechanophore in order to derive percent activation.

\section{Tabulated Data for Determined Rate Constants and $M_{\text {thresh }}$ Values}

Table S2. Rate constants and standard deviation for all ultrasonication experiments.

\begin{tabular}{|c|c|c|c|c|c|c|}
\hline & $\begin{array}{l}M_{\mathrm{n}, 0} \\
(\mathrm{kDa})\end{array}$ & $\begin{array}{l}k_{\mathrm{PL}} \\
\times 10^{-3}\left(\mathrm{~min}^{-1}\right)\end{array}$ & $\begin{array}{l}k_{\mathrm{M}} \\
\mathrm{x} 10^{-3}\left(\mathrm{~min}^{-1}\right)\end{array}$ & $\begin{array}{l}k_{\mathrm{RI}} \\
\times 10^{-3}\left(\mathrm{~min}^{-1}\right)\end{array}$ & $\begin{array}{l}k_{\mathrm{L}} \text { (first half) } \\
\times 10^{-6}\left(\mathrm{~min}^{-1}\right)\end{array}$ & $\begin{array}{l}k_{\mathrm{L}} \text { (full time) } \\
\times 10^{-6}\left(\mathrm{~min}^{-1}\right)\end{array}$ \\
\hline \multirow{8}{*}{ PMA-1 } & 43.3 & $2.3 \pm 0.3$ & -- & -- & -- & -- \\
\hline & 70.7 & $6.4 \pm 0.1$ & $8.0 \pm 0.6$ & $4.5 \pm 0.1$ & $5.2 \pm 0.1$ & $4.5 \pm 0.3$ \\
\hline & 87.1 & $11.5 \pm 0.4$ & $15.6 \pm 1.2$ & $8.4 \pm 0.5$ & $8.0 \pm 0.3$ & $6.7 \pm 0.2$ \\
\hline & 108 & $18.0 \pm 1.4$ & $24.3 \pm 1.5$ & $14.0 \pm 0.5$ & $10.3 \pm 0.05$ & $8.0 \pm 0.2$ \\
\hline & 139 & $32.6 \pm 1.5$ & $44.6 \pm 0.9$ & $28.5 \pm 1.1$ & $14.8 \pm 0.5$ & $11.8 \pm 0.2$ \\
\hline & 159 & $40.2 \pm 2.7$ & $55.2 \pm 3.0$ & $34.8 \pm 2.1$ & $16.8 \pm 0.3$ & $13.9 \pm 0.3$ \\
\hline & 201 & $69.2 \pm 4.0$ & $85.3 \pm 3.8$ & $65.2 \pm 0.9$ & $25.1 \pm 0.8$ & $20.0 \pm 0.3$ \\
\hline & 221 & $73.5 \pm 3.8$ & $104.8 \pm 4.7$ & $68.2 \pm 3.1$ & $27.3 \pm 0.4$ & $22.1 \pm 0.3$ \\
\hline \multirow{6}{*}{$\begin{array}{l}\text { PMA-2 } \\
\text { in 3:1 } \\
\text { MeCN/ } \\
\text { MeOH }\end{array}$} & 78.7 & $5.0 \pm 0.3$ & $6.0 \pm 0.5$ & $2.9 \pm 0.1$ & $2.9 \pm 0.2$ & $2.3 \pm 0.1$ \\
\hline & 111 & $14.5 \pm 2.1$ & $17.3 \pm 1.8$ & $11.7 \pm 1.9$ & $8.1 \pm 0.7$ & $6.4 \pm 0.2$ \\
\hline & 132 & $26.6 \pm 0.3$ & $29.2 \pm 2.8$ & $25.0 \pm 0.6$ & $12.8 \pm 0.6$ & $10.2 \pm 0.2$ \\
\hline & 160 & $37.2 \pm 1.2$ & $40.9 \pm 3.1$ & $35.4 \pm 3.3$ & $12.9 \pm 0.2$ & $10.4 \pm 0.2$ \\
\hline & 180 & $44.8 \pm 1.2$ & $56.5 \pm 2.3$ & $44.5 \pm 2.4$ & $21.2 \pm 0.9$ & $16.9 \pm 0.5$ \\
\hline & 206 & $52.2 \pm 6.0$ & $64.7 \pm 5.8$ & $47.1 \pm 5.0$ & $21.1 \pm 1.9$ & $16.2 \pm 1.4$ \\
\hline
\end{tabular}


Table S3. Values of $M_{\text {thresh }}(\mathrm{kDa})$ calculated from linear regressions of specified rate constants.

\begin{tabular}{r|l|l|l|l|l} 
& $\boldsymbol{k}_{\mathrm{PL}}$ & $\boldsymbol{k}_{\mathrm{RI}}$ & $\boldsymbol{k}_{\mathrm{M}}$ & $\boldsymbol{k}_{\mathrm{L}}$ (first half) & $\boldsymbol{k}_{\mathrm{L}}$ (full time) \\
\hline PMA-1 in THF & 65 & 71 & 65 & 37 & 36 \\
\hline PMA-2 in MeCN/MeOH & 67 & 71 & 71 & 56 & 55 \\
\hline
\end{tabular}

VII. Tabulated Characterization Data for All Sonication Experiments

Table S4. PL intensity $\left(\lambda_{\mathrm{em}}=413 \mathrm{~nm}\right)$ for PMA-1 $\left(M_{\mathrm{n}}=43.3 \mathrm{kDa}\right)$ upon ultrasonication in THF.

\begin{tabular}{l|l|l|l|}
$\begin{array}{l}\text { Sonication } \\
\text { time (min) }\end{array}$ & Trial 1 & Trial 2 & Trial 3 \\
\hline $\mathbf{0}$ & 103 & 52 & 54 \\
$\mathbf{6 0}$ & 7103 & 7910 & 6782 \\
$\mathbf{1 2 0}$ & 12722 & 14111 & 12549 \\
$\mathbf{1 8 0}$ & 18091 & 20067 & 17689 \\
$\mathbf{2 4 0}$ & 23432 & 24648 & 22464 \\
$\mathbf{3 6 0}$ & 31164 & 32365 & 30680 \\
$\mathbf{4 8 0}$ & 38003 & 37654 & 35952 \\
$\mathbf{6 0 0}$ & 43768 & 41284 & 40780 \\
$\mathbf{7 2 0}$ & 43668 & 45002 & 44404 \\
$\mathbf{8 4 0}$ & 45570 & 47916 & 48538 \\
$\mathbf{9 6 0}$ & 48437 & 50477 & 51020
\end{tabular}

Table S5. Determined $M_{\mathrm{n}}(\mathrm{kDa})$, PL intensity $\left(\lambda_{\mathrm{em}}=413 \mathrm{~nm}\right)$, and RI response for PMA-1 $\left(M_{\mathrm{n}}=70.7 \mathrm{kDa}\right)$ upon ultrasonication in THF.

\begin{tabular}{|c|c|c|c|c|c|c|c|c|c|}
\hline \multirow[b]{2}{*}{$\begin{array}{l}\text { Sonication } \\
\text { time (min) }\end{array}$} & \multicolumn{3}{|c|}{ Trial 1} & \multicolumn{3}{|c|}{ Trial 2} & \multicolumn{3}{|c|}{ Trial 3} \\
\hline & $M_{n}$ & PL & $\mathbf{R I}$ & $M_{n}$ & PL & $\mathbf{R I}$ & $M_{n}$ & PL & $\mathbf{R I}$ \\
\hline 0 & 71.3 & 60 & 1.39 & 71.7 & 55 & 1.33 & 69.2 & 61 & 1.32 \\
\hline 20 & 63.6 & 6161 & 1.29 & 64.0 & 5770 & 1.23 & 65.0 & 6729 & 1.24 \\
\hline 40 & 59.7 & 11106 & 1.21 & 60.9 & 10317 & 1.17 & 59.2 & 11422 & 1.15 \\
\hline 80 & 51.9 & 20030 & 1.00 & 51.1 & 19020 & 0.94 & 51.1 & 19544 & 0.95 \\
\hline 120 & 47.8 & 26745 & 0.83 & 48.5 & 26028 & 0.79 & 46.3 & 26497 & 0.78 \\
\hline 160 & 42.1 & 32288 & 0.68 & 43.3 & 31410 & 0.65 & 42.2 & 31269 & 0.65 \\
\hline 200 & 37.5 & 36354 & 0.56 & 40.0 & 35599 & 0.54 & 40.5 & 34620 & 0.55 \\
\hline 240 & 37.3 & 38846 & 0.46 & 38.5 & 38574 & 0.47 & 37.0 & 37645 & 0.48 \\
\hline 280 & 34.7 & 41164 & 0.40 & 37.6 & 40839 & 0.42 & 37.7 & 39791 & 0.40 \\
\hline 320 & 33.6 & 43506 & 0.34 & 35.0 & 41614 & 0.34 & 36.0 & 41857 & 0.34 \\
\hline
\end{tabular}


Table S6. Determined $M_{n}(k D a)$, PL intensity $\left(\lambda_{e m}=413 \mathrm{~nm}\right)$, and RI response for PMA-1 $\left(M_{n}=87.1 \mathrm{kDa}\right)$ upon ultrasonication in THF.

\begin{tabular}{|c|c|c|c|c|c|c|c|c|c|}
\hline \multirow[b]{2}{*}{$\begin{array}{l}\text { Sonication } \\
\text { time (min) }\end{array}$} & \multicolumn{3}{|c|}{ Trial 1} & \multicolumn{3}{|c|}{ Trial 2} & \multicolumn{3}{|c|}{ Trial 3} \\
\hline & $M_{n}$ & PL & $\mathbf{R I}$ & $M_{n}$ & $\mathrm{PL}$ & RI & $M_{\mathrm{n}}$ & $\mathrm{PL}$ & $\mathbf{R I}$ \\
\hline 0 & 87.1 & -- & 1.47 & 86.6 & -- & 1.47 & 87.8 & 79 & 1.43 \\
\hline 10 & 80.5 & 4204 & 1.36 & 81.8 & 4097 & 1.38 & 79.7 & 4522 & 1.32 \\
\hline 20 & 75.0 & 8005 & 1.27 & 75.1 & 7492 & 1.27 & 74.2 & 8442 & 1.24 \\
\hline 40 & 64.7 & 14719 & 1.05 & 64.2 & 14271 & 1.06 & 65.1 & 15018 & 1.05 \\
\hline 60 & 59.3 & 20288 & 0.86 & 59.9 & 19756 & 0.88 & 57.5 & 20518 & 0.88 \\
\hline 80 & 51.7 & 24548 & 0.72 & 52.5 & 23639 & 0.73 & 51.8 & 24775 & 0.75 \\
\hline 100 & 50.1 & 27654 & 0.61 & 48.3 & 26815 & 0.62 & 48.2 & 28062 & 0.64 \\
\hline 120 & 46.6 & 30010 & 0.51 & 48.0 & 29032 & 0.51 & 45.5 & 30684 & 0.54 \\
\hline 140 & 43.7 & 32185 & 0.45 & 44.8 & 30815 & 0.45 & 45.1 & 33072 & 0.49 \\
\hline 160 & 43.4 & 33646 & 0.38 & 43.3 & 32938 & 0.38 & 43.8 & 34640 & 0.43 \\
\hline 180 & 40.6 & 34889 & 0.32 & 42.4 & 34930 & 0.31 & 41.8 & 35479 & 0.38 \\
\hline
\end{tabular}

Table S7. Determined $M_{\mathrm{n}}(\mathrm{kDa}), \mathrm{PL}$ intensity $\left(\lambda_{\mathrm{em}}=413 \mathrm{~nm}\right)$, and RI response for PMA-1 $\left(M_{\mathrm{n}}=108 \mathrm{kDa}\right)$ upon ultrasonication in THF.

\begin{tabular}{|c|c|c|c|c|c|c|c|c|c|}
\hline \multirow[b]{2}{*}{$\begin{array}{l}\text { Sonication } \\
\text { time (min) }\end{array}$} & \multicolumn{3}{|c|}{ Trial 1} & \multicolumn{3}{|c|}{ Trial 2} & \multicolumn{3}{|c|}{ Trial 3} \\
\hline & $M_{\mathrm{n}}$ & PL & $\mathbf{R I}$ & $M_{n}$ & PL & $\mathbf{R I}$ & $M_{n}$ & PL & $\mathbf{R I}$ \\
\hline 0 & 108 & 55 & 1.32 & 109 & 58 & 1.34 & 108 & 49 & 1.35 \\
\hline 10 & 94.6 & 5767 & 1.18 & 96.8 & 5183 & 1.21 & 92.7 & 5687 & 1.19 \\
\hline 20 & 82.7 & 10262 & 1.02 & 83.0 & 9365 & 1.04 & 80.9 & 10114 & 1.03 \\
\hline 40 & 67.8 & 17370 & 0.76 & 69.2 & 16230 & 0.78 & 67.2 & 17129 & 0.77 \\
\hline 60 & 61.1 & 22663 & 0.56 & 61.0 & 21249 & 0.60 & 61.6 & 22418 & 0.56 \\
\hline 80 & 54.4 & 26345 & 0.42 & 54.9 & 24866 & 0.46 & 54.5 & 25304 & 0.43 \\
\hline 100 & 50.8 & 28052 & 0.31 & 51.8 & 27469 & 0.34 & 52.2 & 27685 & 0.31 \\
\hline 120 & 48.2 & 29803 & 0.25 & 48.8 & 29091 & 0.27 & 48.9 & 28785 & 0.26 \\
\hline 140 & 46.1 & 31104 & 0.19 & 46.6 & 30411 & 0.21 & 47.3 & 30305 & 0.19 \\
\hline 160 & 45.7 & 31697 & 0.15 & 43.9 & 31490 & 0.18 & 46.4 & 30828 & 0.15 \\
\hline
\end{tabular}


Table S8. Determined $M_{\mathrm{n}}(\mathrm{kDa}), \mathrm{PL}$ intensity $\left(\lambda_{\mathrm{em}}=413 \mathrm{~nm}\right)$, and RI response for PMA-1 $\left(M_{\mathrm{n}}=139 \mathrm{kDa}\right)$ upon ultrasonication in THF.

\begin{tabular}{|c|c|c|c|c|c|c|c|c|c|}
\hline \multirow[b]{2}{*}{$\begin{array}{l}\text { Sonication } \\
\text { time (min) }\end{array}$} & \multicolumn{3}{|c|}{ Trial 1} & \multicolumn{3}{|c|}{ Trial 2} & \multicolumn{3}{|c|}{ Trial 3} \\
\hline & $M_{n}$ & PL & $\mathbf{R I}$ & $M_{n}$ & PL & $\mathbf{R I}$ & $M_{n}$ & PL & $\mathbf{R I}$ \\
\hline 0 & 137 & -- & 1.49 & 140 & -- & 1.48 & 139 & 59 & 1.39 \\
\hline 5 & 117 & 4149 & 1.30 & 119 & 4300 & 1.31 & 122 & 4208 & 1.24 \\
\hline 10 & 107 & 7464 & 1.14 & 105 & 7780 & 1.13 & 107 & 7436 & 1.10 \\
\hline 20 & 90.7 & 12780 & 0.86 & 90.2 & 13173 & 0.84 & 88.4 & 12924 & 0.83 \\
\hline 30 & 77.2 & 16803 & 0.64 & 78.0 & 17434 & 0.61 & 77.6 & 17269 & 0.62 \\
\hline 40 & 68.6 & 19760 & 0.44 & 70.2 & 20083 & 0.45 & 71.7 & 20260 & 0.46 \\
\hline 50 & 64.6 & 21967 & 0.38 & 65.5 & 21987 & 0.33 & 69.1 & 22815 & 0.34 \\
\hline 60 & 64.0 & 23489 & 0.26 & 65.1 & 22923 & 0.23 & 62.2 & 23980 & 0.27 \\
\hline 70 & 59.2 & 24586 & 0.21 & 59.8 & 24127 & 0.19 & 59.2 & 25200 & 0.21 \\
\hline 80 & 57.7 & 24834 & 0.17 & 57.0 & 25110 & 0.15 & 59.8 & 25961 & 0.15 \\
\hline 90 & 56.1 & 25518 & 0.13 & 54.8 & 25963 & 0.12 & 56.3 & 26552 & 0.12 \\
\hline
\end{tabular}

Table S9. Determined $M_{\mathrm{n}}(\mathrm{kDa}), \mathrm{PL}$ intensity $\left(\lambda_{\mathrm{em}}=413 \mathrm{~nm}\right)$, and RI response for PMA-1 $\left(M_{\mathrm{n}}=159 \mathrm{kDa}\right)$ upon ultrasonication in THF.

\begin{tabular}{|c|c|c|c|c|c|c|c|c|c|}
\hline \multirow[b]{2}{*}{$\begin{array}{l}\text { Sonication } \\
\text { time (min) }\end{array}$} & \multicolumn{3}{|c|}{ Trial 1} & \multicolumn{3}{|c|}{ Trial 2} & \multicolumn{3}{|c|}{ Trial 3} \\
\hline & $M_{n}$ & PL & $\mathbf{R I}$ & $M_{n}$ & PL & $\mathbf{R I}$ & $M_{\mathrm{n}}$ & PL & $\mathbf{R I}$ \\
\hline 0 & 160 & 61 & 1.29 & 160 & 63 & 1.31 & 158 & 45 & 1.34 \\
\hline 5 & 133 & 4274 & 1.13 & 134 & 4217 & 1.14 & 133 & 4593 & 1.12 \\
\hline 10 & 115 & 7625 & 0.99 & 118 & 7523 & 0.98 & 113 & 8030 & 0.94 \\
\hline 15 & 103 & 10448 & 0.83 & 106 & 10306 & 0.81 & 102 & 10889 & 0.78 \\
\hline 20 & 90.6 & 12943 & 0.69 & 95.1 & 12725 & 0.66 & 92.5 & 13232 & 0.65 \\
\hline 30 & 83.0 & 16375 & 0.48 & 82.3 & 16445 & 0.45 & 81.4 & 16588 & 0.44 \\
\hline 40 & 74.5 & 18771 & 0.34 & 74.5 & 18316 & 0.30 & 73.4 & 18850 & 0.31 \\
\hline 50 & 67.9 & 20190 & 0.25 & 71.0 & 19804 & 0.20 & 66.0 & 20036 & 0.22 \\
\hline 60 & 65.0 & 21182 & 0.19 & 65.0 & 21750 & 0.15 & 62.0 & 21248 & 0.16 \\
\hline 70 & 62.1 & 22268 & 0.14 & 61.2 & 22213 & 0.11 & 61.9 & 21842 & 0.12 \\
\hline
\end{tabular}


Table S10. Determined $M_{n}(\mathrm{kDa}), \mathrm{PL}$ intensity $\left(\lambda_{\mathrm{em}}=413 \mathrm{~nm}\right)$, and RI response for PMA-1 $\left(M_{\mathrm{n}}=201 \mathrm{kDa}\right)$ upon ultrasonication in THF.

\begin{tabular}{|c|c|c|c|c|c|c|c|c|c|}
\hline \multirow[b]{2}{*}{$\begin{array}{l}\text { Sonication } \\
\text { time (min) }\end{array}$} & \multicolumn{3}{|c|}{ Trial 1} & \multicolumn{3}{|c|}{ Trial 2} & \multicolumn{3}{|c|}{ Trial 3} \\
\hline & $M_{n}$ & PL & $\mathbf{R I}$ & $M_{n}$ & PL & $\mathbf{R I}$ & $M_{n}$ & PL & $\mathbf{R I}$ \\
\hline 0 & 197 & 54 & 1.36 & 202 & 57 & 1.37 & 202 & 49 & 1.36 \\
\hline 5 & 147 & 5286 & 1.02 & 147 & 5730 & 1.04 & 155 & 5387 & 1.06 \\
\hline 10 & 121 & 9249 & 0.74 & 119 & 9697 & 0.74 & 124 & 9103 & 0.79 \\
\hline 15 & 103 & 12153 & 0.51 & 106 & 12578 & 0.53 & 107 & 12023 & 0.55 \\
\hline 20 & 90.2 & 14251 & 0.36 & 89.8 & 14375 & 0.38 & 92.6 & 13855 & 0.38 \\
\hline 25 & 82.8 & 15530 & 0.25 & 83.3 & 15805 & 0.27 & 87.0 & 15458 & 0.25 \\
\hline 30 & 78.8 & 16811 & -- & 78.2 & 16732 & 0.20 & 77.3 & 16420 & 0.17 \\
\hline 35 & 74.0 & 17312 & 0.13 & 74.3 & 17405 & 0.14 & 75.7 & 17167 & 0.12 \\
\hline 40 & 68.7 & 17891 & 0.09 & 70.5 & 17666 & 0.10 & 75.1 & 17446 & 0.08 \\
\hline 45 & 66.6 & -- & 0.06 & 69.3 & 18092 & 0.07 & 69.3 & 17909 & 0.06 \\
\hline 50 & 65.6 & 18360 & 0.05 & 65.5 & 18117 & 0.05 & 65.4 & 18213 & 0.04 \\
\hline
\end{tabular}

Table S11. Determined $M_{\mathrm{n}}(\mathrm{kDa}), \mathrm{PL}$ intensity $\left(\lambda_{\mathrm{em}}=413 \mathrm{~nm}\right)$, and RI response for PMA-1 $\left(M_{\mathrm{n}}=221 \mathrm{kDa}\right)$ upon ultrasonication in THF.

\begin{tabular}{|c|c|c|c|c|c|c|c|c|c|}
\hline \multirow[b]{2}{*}{$\begin{array}{l}\text { Sonication } \\
\text { time (min) }\end{array}$} & \multicolumn{3}{|c|}{ Trial 1} & \multicolumn{3}{|c|}{ Trial 2} & \multicolumn{3}{|c|}{ Trial 3} \\
\hline & $M_{n}$ & PL & $\mathbf{R I}$ & $M_{n}$ & PL & $\mathbf{R I}$ & $M_{n}$ & PL & $\mathbf{R I}$ \\
\hline 0 & 221 & 57 & 1.20 & 220 & 41 & 1.22 & 223 & 53 & 1.19 \\
\hline 3.33 & 167 & 3782 & 0.99 & 173 & 3674 & 1.00 & 174 & 3717 & 1.01 \\
\hline 6.66 & 141 & 6716 & 0.81 & 143 & 6438 & 0.81 & 145 & 6673 & 0.82 \\
\hline 10 & 124 & 8907 & 0.63 & 128 & 8680 & 0.65 & 126 & 8952 & 0.65 \\
\hline 15 & 107 & 11393 & 0.40 & 109 & 11202 & 0.43 & 108 & 11367 & 0.46 \\
\hline 20 & 95.7 & 13341 & 0.27 & 94.6 & 13170 & 0.31 & 93.9 & 13179 & 0.32 \\
\hline 25 & 88.3 & 14441 & 0.19 & 87.5 & 14234 & 0.21 & 85.8 & 14363 & 0.23 \\
\hline 30 & 80.8 & 15237 & 0.13 & 81.5 & 15321 & 0.15 & 84.0 & 15028 & 0.15 \\
\hline 35 & 74.5 & 15778 & 0.11 & 77.5 & 15929 & 0.11 & 78.3 & 15544 & 0.11 \\
\hline 40 & 72.6 & 16046 & 0.08 & 71.2 & 16332 & 0.09 & 74.6 & 16041 & 0.09 \\
\hline
\end{tabular}


Table S12. Determined $M_{\mathrm{n}}(\mathrm{kDa}), \mathrm{PL}$ intensity $\left(\lambda_{\mathrm{em}}=375 \mathrm{~nm}\right)$, and RI response for PMA-2 $\left(M_{\mathrm{n}}=78.7 \mathrm{kDa}\right)$ upon ultrasonication in 3:1 MeCN/MeOH.

\begin{tabular}{|c|c|c|c|c|c|c|c|c|c|}
\hline \multirow[b]{2}{*}{$\begin{array}{l}\text { Sonication } \\
\text { time (min) }\end{array}$} & \multicolumn{3}{|c|}{ Trial 1} & \multicolumn{3}{|c|}{ Trial 2} & \multicolumn{3}{|c|}{ Trial 3} \\
\hline & $M_{n}$ & PL & $\mathbf{R I}$ & $M_{n}$ & PL & $\mathbf{R I}$ & $M_{\mathrm{n}}$ & PL & $\mathbf{R I}$ \\
\hline 0 & 78.8 & 324.8 & 1.32 & 78.5 & 303.1 & 1.31 & 78.7 & 330.5 & 1.35 \\
\hline 40 & 68.9 & 1753.1 & 1.18 & 71.8 & 1716.5 & 1.21 & 70.8 & 1651.4 & 1.23 \\
\hline 80 & 60.7 & 2898.8 & 1.03 & 63.4 & 2906.8 & 1.06 & 64.5 & 2727.8 & 1.09 \\
\hline 120 & 57.1 & 3908.9 & 0.91 & 56.8 & 3870.0 & 0.94 & 58.2 & 3762.5 & 0.96 \\
\hline 160 & 54.6 & 4649.0 & 0.81 & 53.5 & 4746.0 & 0.82 & 54.4 & 4458.3 & 0.85 \\
\hline 200 & 52.7 & 5365.1 & 0.72 & 49.7 & 5374.2 & 0.73 & 53.2 & 5116.6 & 0.77 \\
\hline 280 & 46.5 & 6332.0 & 0.58 & 45.4 & 6438.3 & 0.57 & 48.1 & 6071.6 & 0.63 \\
\hline 400 & 44.1 & 7286.1 & 0.42 & 41.9 & 7456.1 & 0.40 & 43.8 & 7130.5 & 0.45 \\
\hline 440 & 41.8 & 7654.6 & 0.38 & 41.1 & 7560.6 & 0.38 & 42.3 & 7537.2 & 0.40 \\
\hline 480 & 41.0 & 7783.4 & 0.32 & 40.2 & 7644.0 & 0.34 & 40.9 & 7853.6 & 0.36 \\
\hline
\end{tabular}

Table S13. Determined $M_{\mathrm{n}}(\mathrm{kDa}), \mathrm{PL}$ intensity $\left(\lambda_{\mathrm{em}}=375 \mathrm{~nm}\right)$, and RI response for PMA-2 $\left(M_{\mathrm{n}}=111 \mathrm{kDa}\right)$ upon ultrasonication in 3:1 $\mathrm{MeCN} / \mathrm{MeOH}$.

\begin{tabular}{|c|c|c|c|c|c|c|c|c|c|}
\hline \multirow[b]{2}{*}{$\begin{array}{l}\text { Sonication } \\
\text { time (min) }\end{array}$} & \multicolumn{3}{|c|}{ Trial 1} & \multicolumn{3}{|c|}{ Trial 2} & \multicolumn{3}{|c|}{ Trial 3} \\
\hline & $M_{\mathrm{n}}$ & $\mathrm{PL}$ & $\mathbf{R I}$ & $M_{\mathrm{n}}$ & $\mathrm{PL}$ & $\mathbf{R I}$ & $M_{\mathrm{n}}$ & $\mathrm{PL}$ & $\mathbf{R} \mathbf{I}$ \\
\hline 0 & 110 & 229.9 & 1.41 & 111 & 234.2 & 1.39 & 113 & 248.5 & 1.31 \\
\hline 20 & 82.4 & 1815.2 & 1.08 & 88.1 & 1710.4 & 1.13 & 91.1 & 1492.4 & 1.11 \\
\hline 40 & 72.3 & 2913.2 & 0.81 & 74.8 & 2851.4 & 0.88 & 79.4 & 2532.6 & 0.91 \\
\hline 80 & 57.9 & 4266.1 & 0.48 & 60.1 & 4308.0 & 0.51 & 63.5 & 3958.7 & 0.60 \\
\hline 120 & 51.6 & 5027.4 & 0.27 & 51.4 & 5220.1 & 0.31 & 56.4 & 4792.0 & 0.40 \\
\hline 160 & 45.3 & 5469.0 & 0.16 & 46.8 & 5725.0 & 0.19 & 50.7 & 5398.8 & 0.28 \\
\hline 200 & 43.9 & 5744.3 & 0.12 & 43.8 & 6077.4 & 0.13 & 46.2 & 5604.8 & 0.19 \\
\hline 240 & 41.4 & 5765.3 & 0.08 & 42.5 & 6245.9 & 0.10 & 44.9 & 5939.7 & 0.15 \\
\hline 260 & 40.7 & 5919.6 & 0.06 & 41.3 & 6247.6 & 0.06 & 43.8 & 6222.2 & 0.13 \\
\hline
\end{tabular}


Table S14. Determined $M_{\mathrm{n}}(\mathrm{kDa}), \mathrm{PL}$ intensity $\left(\lambda_{\mathrm{em}}=375 \mathrm{~nm}\right)$, and RI response for PMA-2 $\left(M_{\mathrm{n}}=132 \mathrm{kDa}\right)$ upon ultrasonication in 3:1 MeCN/MeOH.

\begin{tabular}{|c|c|c|c|c|c|c|c|c|c|}
\hline \multirow[b]{2}{*}{$\begin{array}{l}\text { Sonication } \\
\text { time (min) }\end{array}$} & \multicolumn{3}{|c|}{ Trial 1} & \multicolumn{3}{|c|}{ Trial 2} & \multicolumn{3}{|c|}{ Trial 3} \\
\hline & $M_{n}$ & PL & $\mathbf{R I}$ & $M_{n}$ & PL & $\mathbf{R I}$ & $M_{n}$ & PL & $\mathbf{R I}$ \\
\hline 0 & 131 & 209.0 & 1.31 & 132 & 222.2 & 1.30 & 133 & 238.3 & 1.30 \\
\hline 10 & 107 & 1257.0 & 1.06 & 102 & 1418.0 & 1.03 & 99.9 & 1418.9 & 1.01 \\
\hline 20 & 92.0 & 2083.1 & 0.83 & 86.1 & 2269.9 & 0.79 & 87.7 & 2220.4 & 0.80 \\
\hline 40 & 72.9 & 3245.2 & 0.50 & 69.3 & 3350.3 & 0.46 & 72.0 & 3213.2 & 0.47 \\
\hline 60 & 63.0 & 3982.5 & 0.29 & 61.5 & 4044.6 & 0.27 & 64.3 & 3847.6 & 0.29 \\
\hline 80 & 56.4 & 4281.2 & 0.17 & 55.1 & 4433.6 & 0.16 & 57.5 & 4201.8 & 0.18 \\
\hline 100 & 53.1 & 4621.7 & 0.10 & 50.7 & 4642.4 & 0.11 & 52.9 & 4500.7 & 0.11 \\
\hline 120 & 48.5 & 4742.8 & 0.07 & 48.9 & 4753.9 & 0.07 & 48.9 & 4728.9 & 0.07 \\
\hline 140 & 46.7 & 4875.0 & 0.05 & 44.9 & 5132.0 & 0.05 & 46.3 & 4875.3 & 0.05 \\
\hline 160 & 43.7 & 4955.9 & 0.03 & 44.7 & 5202.6 & 0.03 & 44.9 & 4921.6 & 0.04 \\
\hline 180 & 41.5 & 5079.6 & 0.03 & 41.4 & 5249.5 & 0.03 & 43.5 & 5098.2 & 0.02 \\
\hline
\end{tabular}

Table S15. Determined $M_{\mathrm{n}}(\mathrm{kDa}), \mathrm{PL}$ intensity $\left(\lambda_{\mathrm{em}}=375 \mathrm{~nm}\right)$, and RI response for PMA-2 $\left(M_{\mathrm{n}}=160 \mathrm{kDa}\right)$ upon ultrasonication in 3:1 MeCN/MeOH.

\begin{tabular}{|c|c|c|c|c|c|c|c|c|c|}
\hline \multirow[b]{2}{*}{$\begin{array}{l}\text { Sonication } \\
\text { time (min) }\end{array}$} & \multicolumn{3}{|c|}{ Trial 1} & \multicolumn{3}{|c|}{ Trial 2} & \multicolumn{3}{|c|}{ Trial 3} \\
\hline & $M_{n}$ & PL & $\mathbf{R} \mathbf{I}$ & $M_{n}$ & PL & $\mathbf{R I}$ & $M_{n}$ & PL & $\mathbf{R} \mathbf{I}$ \\
\hline 0 & 156 & 152.0 & 1.27 & 160 & 179.12 & 1.27 & 163 & 218.3 & 1.27 \\
\hline 10 & 118 & 1412.5 & 0.91 & 117 & 1411.6 & 0.91 & 116 & 1435.7 & 0.92 \\
\hline 20 & 96.2 & 2260.0 & 0.61 & 93.5 & 2339.8 & 0.61 & 96.7 & 2258.5 & 0.66 \\
\hline 40 & 75.7 & 3293.4 & 0.26 & 73.2 & 3276.4 & 0.27 & 75.8 & 3220.4 & 0.35 \\
\hline 60 & 65.0 & 3753.7 & 0.12 & 63.3 & 3663.7 & 0.13 & 66.0 & 3569.3 & 0.19 \\
\hline 80 & 57.6 & 4010.9 & 0.07 & 58.2 & 3918.8 & 0.07 & 58.0 & 3854.4 & 0.12 \\
\hline 100 & 52.5 & 4266.2 & 0.04 & 53.1 & 4115.5 & 0.04 & 54.3 & 3984.8 & 0.08 \\
\hline 120 & 50.0 & 4309.1 & 0.03 & 49.6 & 4299.7 & 0.03 & 51.2 & 4161.0 & 0.05 \\
\hline 140 & 46.8 & 4354.4 & 0.02 & 46.4 & 4419.4 & 0.02 & 48.4 & 4227.5 & 0.03 \\
\hline 160 & 45.3 & 4302.0 & 0.01 & 44.2 & 4266.4 & 0.02 & 44.4 & 4237.5 & 0.02 \\
\hline
\end{tabular}


Table S16. Determined $M_{\mathrm{n}}(\mathrm{kDa}), \mathrm{PL}$ intensity $\left(\lambda_{\mathrm{em}}=375 \mathrm{~nm}\right)$, and RI response for PMA-2 $\left(M_{\mathrm{n}}=180 \mathrm{kDa}\right)$ upon ultrasonication in 3:1 MeCN/MeOH.

\begin{tabular}{|c|c|c|c|c|c|c|c|c|c|}
\hline \multirow[b]{2}{*}{$\begin{array}{l}\text { Sonication } \\
\text { time (min) }\end{array}$} & \multicolumn{3}{|c|}{ Trial 1} & \multicolumn{3}{|c|}{ Trial 2} & \multicolumn{3}{|c|}{ Trial 3} \\
\hline & $M_{n}$ & PL & $\mathbf{R I}$ & $M_{n}$ & PL & $\mathbf{R I}$ & $M_{\mathrm{n}}$ & PL & $\mathbf{R} \mathbf{I}$ \\
\hline 0 & 179 & 145.4 & 1.38 & 181 & 145.4 & 1.37 & 180 & 146.3 & 1.38 \\
\hline 5 & 146 & 906.1 & 1.15 & 154 & 861.0 & 1.12 & 148 & 816.2 & 1.15 \\
\hline 10 & 123 & 1549.2 & 0.94 & 124 & 1466.5 & 0.96 & 123 & 1413.7 & 0.92 \\
\hline 20 & 97.9 & 2465.6 & 0.59 & 92.4 & 2468.7 & 0.61 & 97.9 & 2240.4 & 0.56 \\
\hline 30 & 81.5 & 3071.9 & 0.36 & 81.6 & 3032.5 & 0.38 & 83.0 & 2807.2 & 0.33 \\
\hline 40 & 74.5 & 3454.1 & 0.22 & 72.6 & 3370.3 & 0.24 & 76.8 & 3055.3 & 0.20 \\
\hline 50 & 68.5 & 3763.1 & 0.15 & 66.6 & 3694.9 & 0.15 & 69.2 & 3346.6 & 0.11 \\
\hline 60 & 63.3 & 3963.5 & 0.10 & 63.4 & 3847.1 & 0.09 & 64.4 & 3488.7 & 0.07 \\
\hline 70 & 59.3 & 4046.6 & 0.06 & 59.2 & 3950.5 & 0.06 & 61.8 & 3624.6 & 0.04 \\
\hline 80 & 56.8 & 4159.4 & 0.04 & 56.0 & 3982.3 & 0.04 & 57.4 & 3672.7 & 0.03 \\
\hline
\end{tabular}

Table S17. Determined $M_{\mathrm{n}}(\mathrm{kDa}), \mathrm{PL}$ intensity $\left(\lambda_{\mathrm{em}}=375 \mathrm{~nm}\right)$, and RI response for PMA-2 $\left(M_{\mathrm{n}}=206 \mathrm{kDa}\right)$ upon ultrasonication in 3:1 $\mathrm{MeCN} / \mathrm{MeOH}$.

\begin{tabular}{|c|c|c|c|c|c|c|c|c|c|}
\hline \multirow[b]{2}{*}{$\begin{array}{l}\text { Sonication } \\
\text { time (min) }\end{array}$} & \multicolumn{3}{|c|}{ Trial 1} & \multicolumn{3}{|c|}{ Trial 2} & \multicolumn{3}{|c|}{ Trial 3} \\
\hline & $M_{n}$ & PL & $\mathbf{R I}$ & $M_{\mathrm{n}}$ & PL & RI & $M_{\mathrm{n}}$ & PL & $\mathbf{R} \mathbf{I}$ \\
\hline 0 & 203 & 154.4 & 1.23 & 208 & 136.7 & 1.20 & 206 & 130.3 & 1.22 \\
\hline 5 & 155 & 901.3 & 0.99 & 164 & 877.7 & 1.00 & 159 & 768.6 & 1.03 \\
\hline 10 & 126 & 1450.3 & 0.76 & 140 & 1436.0 & 0.82 & 137 & 1292.6 & 0.83 \\
\hline 20 & 96.3 & 2169.9 & 0.42 & 110 & 2262.1 & 0.51 & 107 & 2050.4 & 0.53 \\
\hline 30 & 82.4 & 2566.8 & 0.24 & 92.8 & 2755.3 & 0.30 & 89.8 & 2489.6 & 0.33 \\
\hline 40 & 76.0 & 2882.3 & 0.15 & 80.9 & 3123.7 & 0.19 & 80.8 & 2794.2 & 0.19 \\
\hline 50 & 68.5 & 2934.9 & 0.09 & 76.2 & 3269.8 & 0.11 & 75.8 & 3004.9 & 0.13 \\
\hline 60 & 64.6 & 3028.1 & 0.06 & 71.6 & 3412.6 & 0.08 & 71.3 & 3098.9 & 0.09 \\
\hline 70 & 60.6 & 3186.6 & 0.03 & 68.0 & 3540.6 & 0.05 & 65.1 & 3207.1 & 0.07 \\
\hline 80 & 57.4 & 3190.6 & 0.03 & 64.0 & 3623.9 & 0.03 & 63.5 & 3264.2 & 0.05 \\
\hline
\end{tabular}




\section{References}

(1) Li, J.; Shiraki, T.; Hu, B.; Wright, R. A. E.; Zhao, B.; Moore, J. S. Mechanophore Activation at Heterointerfaces. J. Am. Chem. Soc. 2014, 136, 15925-15928.

(2) Holden, D. A.; Guillet, J. E. Singlet Electronic Energy Transfer in Polymers Containing Naphthalene and Anthracene Chromophores. Macromolecules 1980, 13, 289-295.

(3) Shaughnessy, K. H.; Kim, P.; Hartwig, J. F. A Fluorescence-Based Assay for High-Throughput Screening of Coupling Reactions. Application to Heck Chemistry. J. Am. Chem. Soc. 1999, 121, 21232132.

(4) Kean, Z. S.; Gossweiler, G. R.; Kouznetsova, T. B.; Hewage, G. B.; Craig, S. L. A Coumarin Dimer Probe of Mechanochemical Scission Efficiency in the Sonochemical Activation of Chain-Centered Mechanophore Polymers. Chem. Commun. 2015, 51, 9157-9160.

(5) Nguyen, N. H.; Rosen, B. M.; Lligadas, G.; Percec, V. Surface-Dependent Kinetics of Cu(0)-WireCatalyzed Single-Electron Transfer Living Radical Polymerization of Methyl Acrylate in DMSO at 25 ${ }^{\circ} \mathrm{C}$. Macromolecules 2009, 42, 2379-2386.

(6) Berkowski, K. L.; Potisek, S. L.; Hickenboth, C. R.; Moore, J. S. Ultrasound-Induced Site-Specific Cleavage of Azo-Functionalized Poly(ethylene glycol). Macromolecules 2005, 38, 8975-8978. 


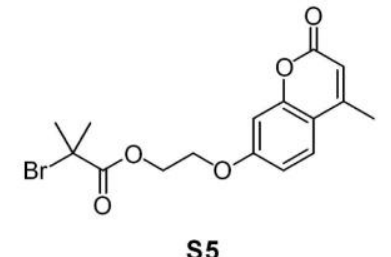

${ }^{1} \mathrm{H}\left(400 \mathrm{MHz}, \mathrm{CDCl}_{3}\right)$

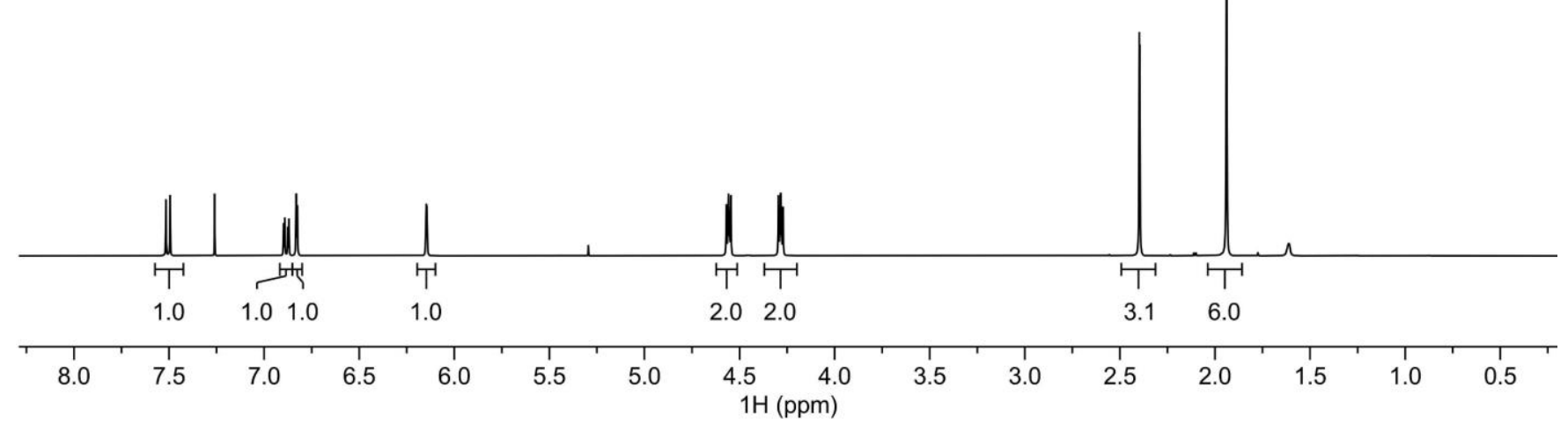

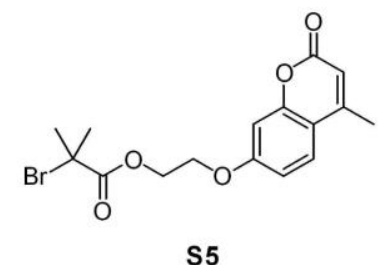

${ }^{13} \mathrm{C}\left(101 \mathrm{MHz}, \mathrm{CDCl}_{3}\right)$
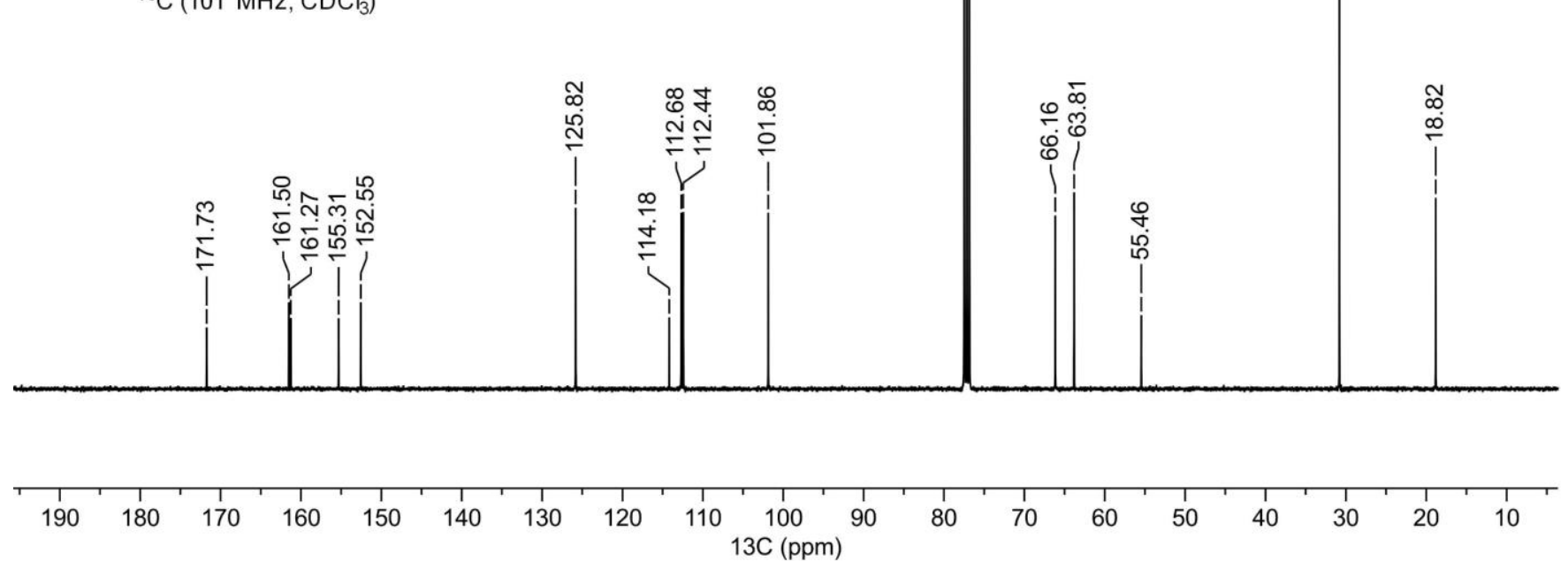

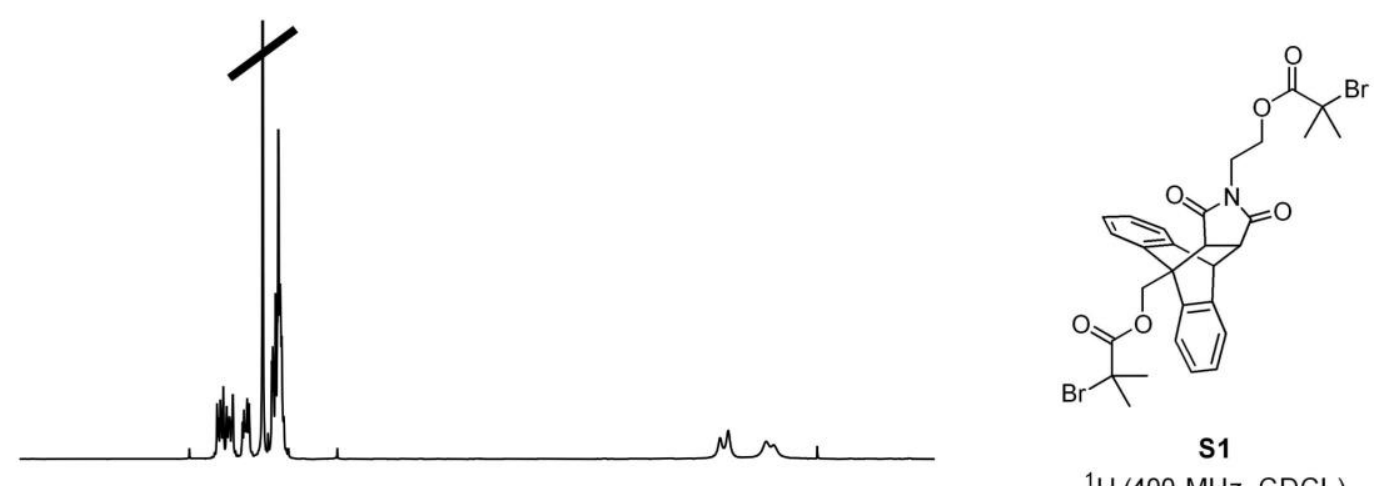

S1

${ }^{1} \mathrm{H}\left(400 \mathrm{MHz}, \mathrm{CDCl}_{3}\right)$
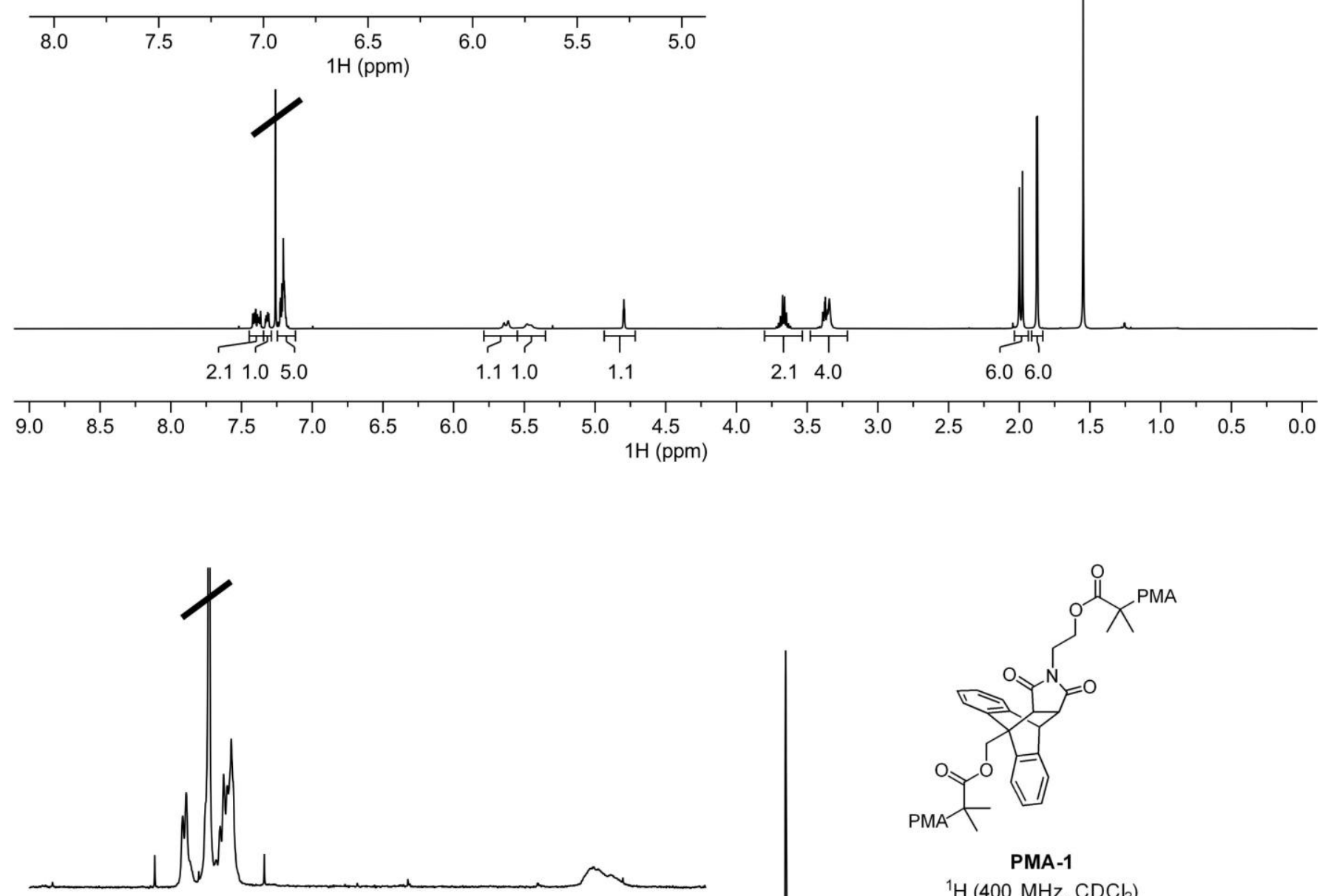

PMA-1

${ }^{1} \mathrm{H}\left(400 \mathrm{MHz}, \mathrm{CDCl}_{3}\right)$

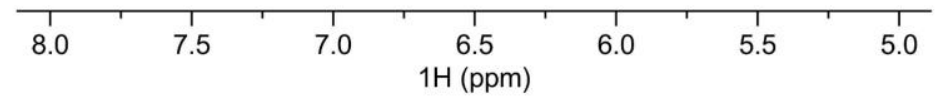

\section{1}

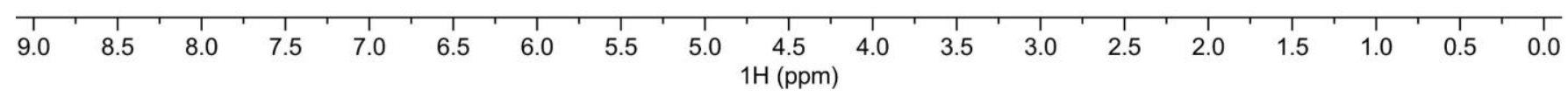



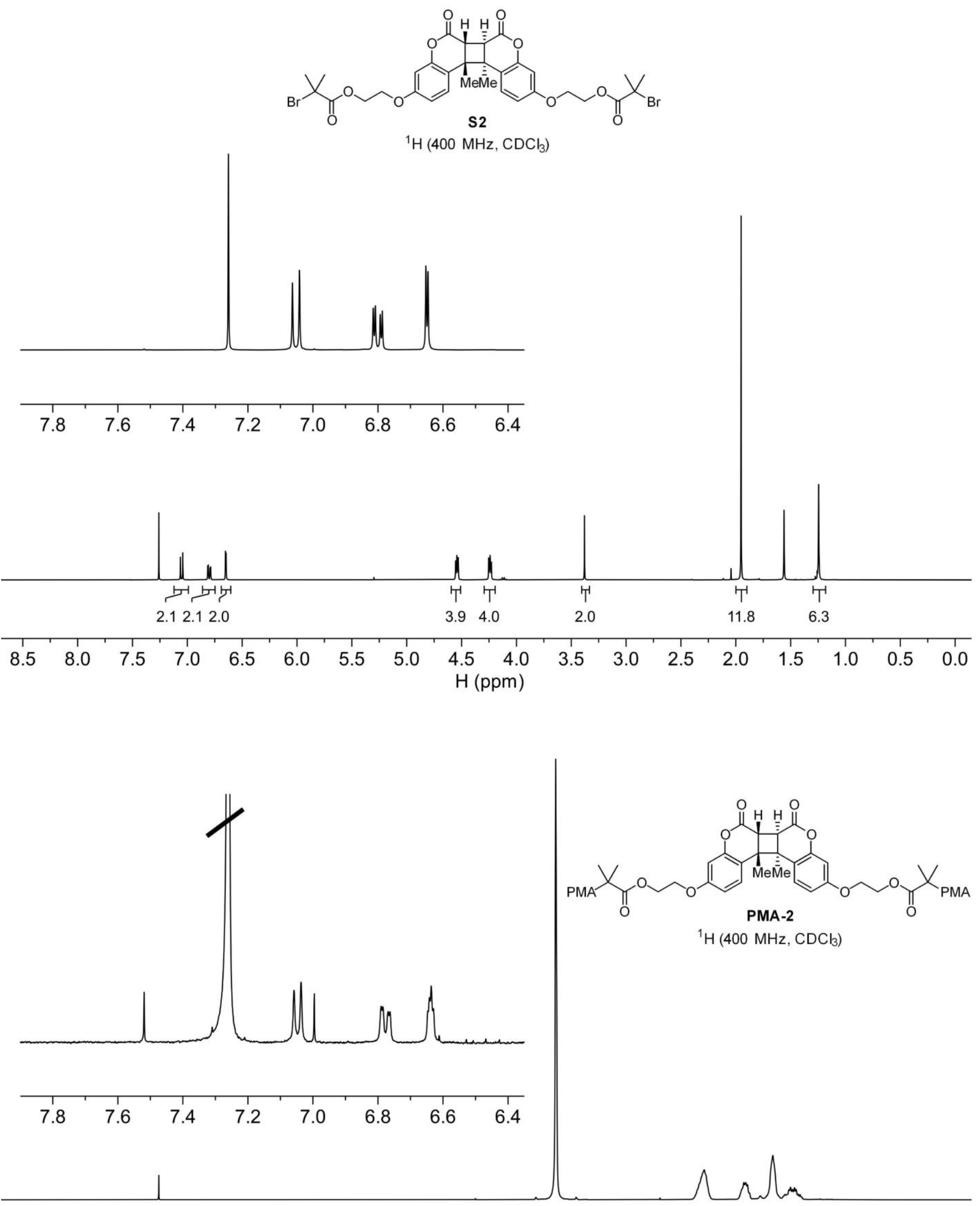

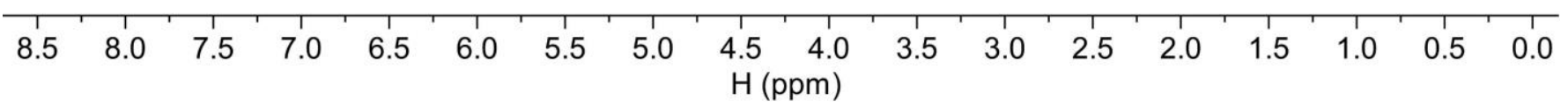



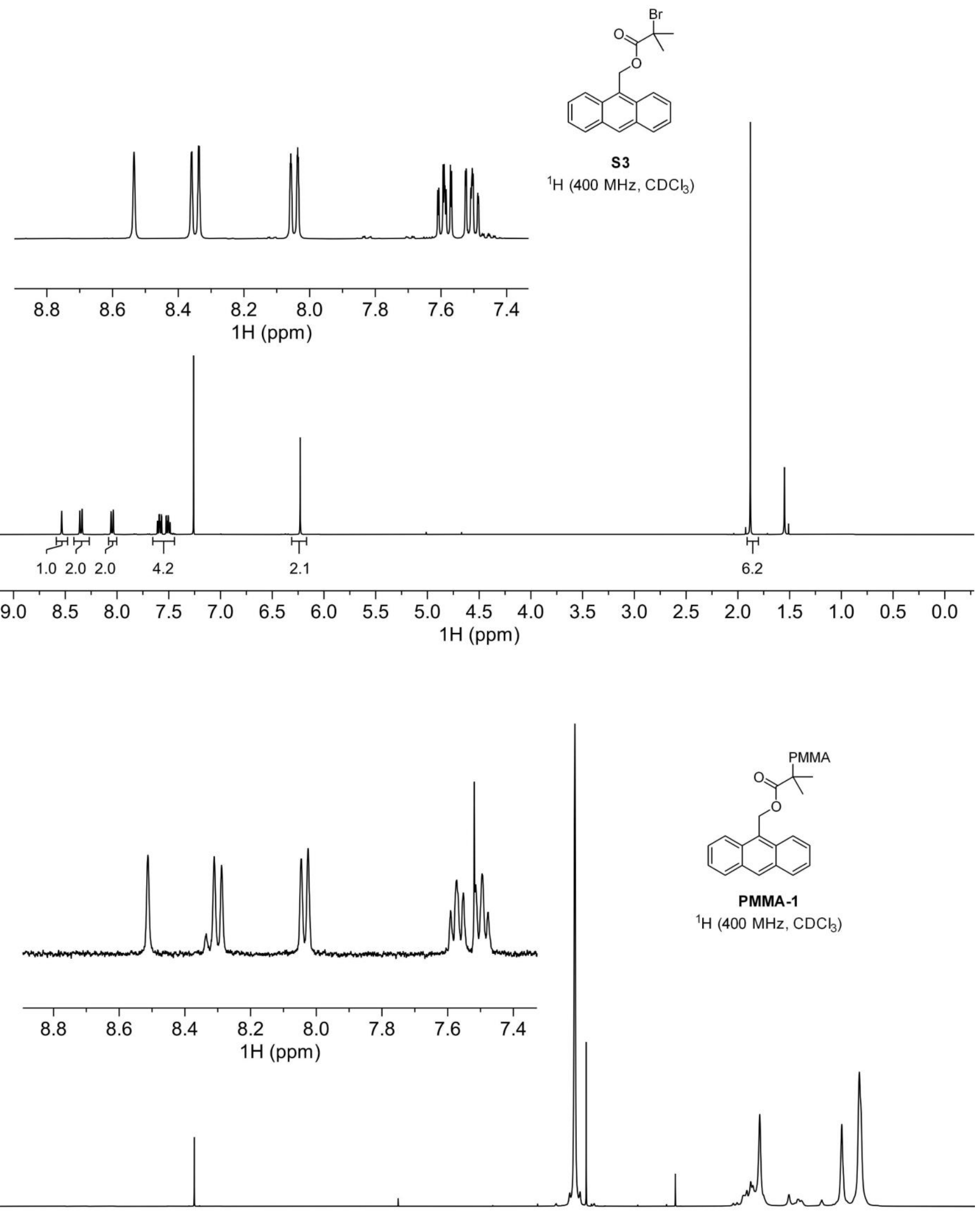

\begin{tabular}{lllllllllllllllllllll}
\hline & 9.0 & 8.5 & 8.0 & 7.5 & 7.0 & 6.5 & 6.0 & 5.5 & 5.0 & 4.5 & 4.0 & 3.5 & 3.0 & 2.5 & 2.0 & 1.5 & 1.0 & 0.5 & 0.0 \\
\hline$(\mathrm{ppm})$ &
\end{tabular} 


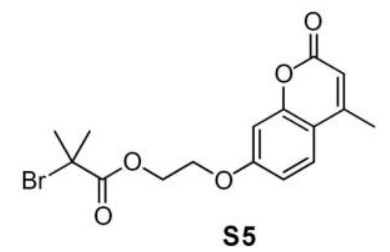

${ }^{1} \mathrm{H}\left(400 \mathrm{MHz}, \mathrm{CDCl}_{3}\right)$
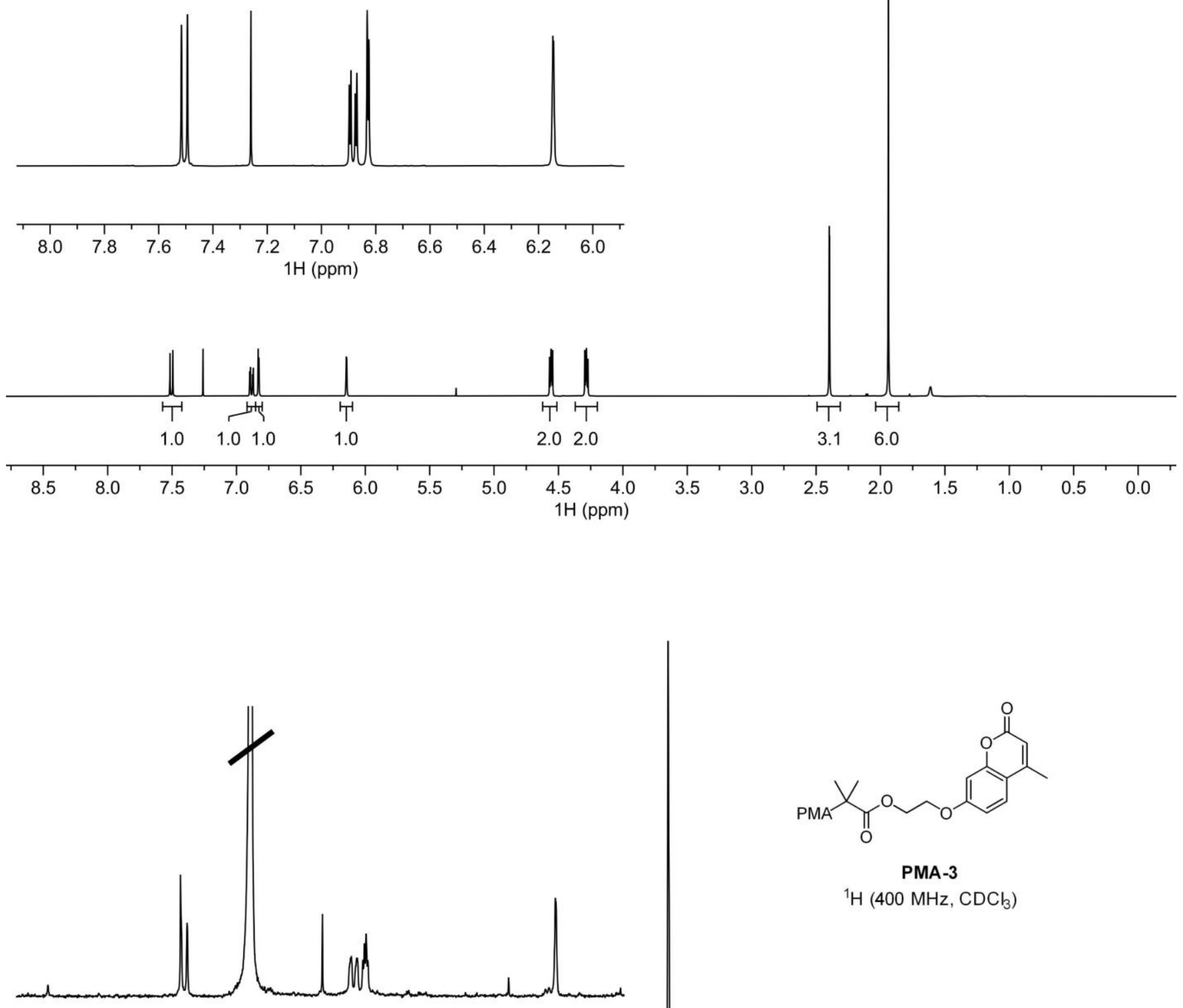

PMA-3

${ }^{1} \mathrm{H}\left(400 \mathrm{MHz}, \mathrm{CDCl}_{3}\right)$
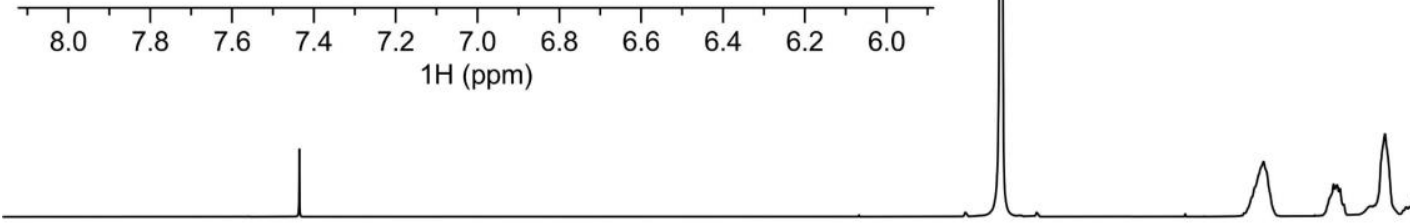

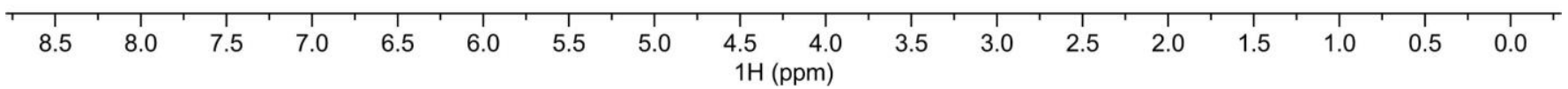

